\title{
Radiative Energy Budgets of Phototrophic Surface-Associated Microbial Communities and their Photosynthetic Efficiency Under Diffuse and Collimated Light
}

\author{
Mads Lichtenberg ${ }^{1 * t}$, Kasper E. Brodersen ${ }^{1 \dagger}$ and Michael Kühl ${ }^{1,2}$ \\ ${ }^{1}$ Marine Biological Section, Department of Biology, University of Copenhagen, Helsingør, Denmark, ${ }^{2}$ Climate Change Cluster, \\ University of Technology Sydney, Ultimo, NSW, Australia
}

OPEN ACCESS

Edited by:

Stefan M. Sievert,

Woods Hole Oceanographic

Institution, USA

Reviewed by:

Markus Huettel,

Florida State University, USA

Lucas Stal,

Royal Netherlands Institute for Sea

Research (NWO), Netherlands

*Correspondence:

Mads Lichtenberg

mads.lichtenberg@bio.ku.dk

${ }^{\dagger}$ These authors have contributed equally to this work.

Specialty section:

This article was submitted to

Aquatic Microbiology,

a section of the journal

Frontiers in Microbiology

Received: 27 January 2017

Accepted: 03 March 2017

Published: 28 March 2017

Citation:

Lichtenberg M, Brodersen KE and Kühl M (2017) Radiative Energy

Budgets of Phototrophic

Surface-Associated Microbial

Communities and their Photosynthetic

Efficiency Under Diffuse and

Collimated Light.

Front. Microbiol. 8:452.

doi: 10.3389/fmicb.2017.00452
We investigated the radiative energy budgets of a heterogeneous photosynthetic coral reef sediment and a compact uniform cyanobacterial biofilm on top of coastal sediment. By combining electrochemical, thermocouple and fiber-optic microsensor measurements of $\mathrm{O}_{2}$, temperature and light, we could calculate the proportion of the absorbed light energy that was either dissipated as heat or conserved by photosynthesis. We show, across a range of different incident light regimes, that such radiative energy budgets are highly dominated by heat dissipation constituting up to $99.5 \%$ of the absorbed light energy. Highest photosynthetic energy conservation efficiency was found in the coral sediment under low light conditions and amounted to $18.1 \%$ of the absorbed light energy. Additionally, the effect of light directionality, i.e., diffuse or collimated light, on energy conversion efficiency was tested on the two surface-associated systems. The effects of light directionality on the radiative energy budgets of these phototrophic communities were not unanimous but, resulted in local spatial differences in heat-transfer, gross photosynthesis, and light distribution. The light acclimation index, $E_{k}$, i.e., the irradiance at the onset of saturation of photosynthesis, was $>2$ times higher in the coral sediment compared to the biofilm and changed the pattern of photosynthetic energy conservation under light-limiting conditions. At moderate to high incident irradiances, the photosynthetic conservation of absorbed energy was highest in collimated light; a tendency that changed in the biofilm under sub-saturating incident irradiances, where higher photosynthetic efficiencies were observed under diffuse light. The aim was to investigate how the physical structure and light propagation affected energy budgets and light utilization efficiencies in loosely organized vs. compact phototrophic sediment under diffuse and collimated light. Our results suggest that the optical properties and the structural organization of phytoelements are important traits affecting the photosynthetic efficiency of biofilms and sediments.

Keywords: biofilm, canopy, coral reef sediment, diffuse and collimated light, heat dissipation, light use efficiency, microsensors, photosynthesis 


\section{INTRODUCTION}

Photosynthetic sediments and biofilms are characterized by pronounced vertical stratification of the microbial environment as a result of steep light gradients, high metabolic activity and limitations of heat and solute transport by diffusion (Kühl et al., 1996; Kühl and Fenchel, 2000; Al-Najjar et al., 2012). The radiative energy balance in such phototrophic microbial communities is affected by the incident radiative energy from the sun, of which a fraction is backscattered and thus not absorbed, while absorbed light energy is either photochemically conserved via photosynthesis or dissipated as heat via radiative energy transfer and non-photochemical quenching (NPQ; Al-Najjar et al., 2010; Brodersen et al., 2014). The quantity and quality of light are the main controlling factors of photosynthesis, and the microscale distribution of light in microphytobenthic systems has been studied intensively over the last decades (Jørgensen and Des Marais, 1988; Lassen et al., 1992a; Kühl and Jørgensen, 1994; Kühl, 2005). A sub-saturating flux of photons will limit the rate of photosynthesis, as the available light is insufficient to support the maximal potential rate of the light reactions. But as the photon flux increases, photosynthesis saturates, whereby $\mathrm{O}_{2}$ becomes a competitive inhibitor on the binding-site of $\mathrm{CO}_{2}$ to Ribulose1,5-bisphosphate carboxylase oxygenase (Rubisco; Falkowski and Raven, 2007). In addition, when light energy absorption exceeds the capacity for light utilization, excess energy is channeled into heat production via NPQ processes to avoid degradation of pigments and other cell constituents e.g., by reactive singlet oxygen produced by the de-excitation of triplet state chlorophyll $\left({ }^{3} \mathrm{Chl}^{*}\right)$ (Müller et al., 2001).

Photosynthetic organisms deploy different mechanisms to avoid photo-damage, where NPQ is an effective short-term solution to dispose of excess energy (Müller et al., 2001). If a photosynthetic cell experiences high light conditions on a daily basis, long-term regulation can be achieved by regulating light harvesting pigment composition and concentration (Nymark et al., 2009). One strategy is to lower the light harvesting pigment content to decrease the absorption cross section by increasing transmittance, while another strategy involves upregulation of photoprotective pigments such as xanthophylls, that absorb energy-rich blue-green light but quench non-photochemically (Zhu et al., 2010).

Since photosynthetic cells perceive light from all directions, the light field angularity is important for determining the total irradiance experienced by a cell (Kühl and Jørgensen, 1994), and it has e.g., been shown that the incident light geometry can influence photosynthetic light use efficiencies and photoinhibition in terrestrial plant canopies (Gu et al., 2002). In sediments, incident light will be spread by multiple scattering and, while the light field will become entirely diffuse with depth (Kühl and Jørgensen, 1994), the response of benthic photosynthetic organisms to incident diffuse light is unknown. Through evaporation, an increase in cloud-cover has been predicted with global warming (Schiermeier, 2006), which will potentially change the direction of light from relatively collimated beams $(\sim 85 \%$ in clear-sky conditions) to a more isotropic diffuse light field ( $\sim 100 \%$ in cloud covered conditions;
Bird and Riordan, 1986; Brodersen et al., 2008; Gorton et al., 2010). In addition, submerged benthic systems will experience temporal and spatial differences in light field isotropy depending on turbidity, water depth, sun angle, and the reflective properties of the surrounding environment (Brakel, 1979; Kirk, 1994; Wangpraseurt and Kühl, 2014).

Increased rates of photosynthesis have been observed in forest communities with an increasing proportion of diffuse light, possibly due to a more even distribution of light in the canopy (Gu et al., 1999; Krakauer and Randerson, 2003; Misson et al., 2005; Urban et al., 2007), whereby light energy is more efficiently harvested from all directions deeper in the canopy. However, at the single leaf scale a $2-3 \%$ lower absorptance was found under diffuse light as compared to collimated light at equivalent incident irradiances (Brodersen and Vogelmann, 2007). In corals, it has been observed that gross photosynthesis increased $\sim 2$-fold under collimated compared to diffuse light of identical downwelling irradiance (Wangpraseurt and Kühl, 2014) and the directional quality of light may thus elicit different photosynthetic responses and could potentially change the photosynthetic efficiency. A factor that could contribute to differences in photosynthetic activity under diffuse and collimated light is photoinhibition, which occurs when the electron transport chain is fully reduced and the photosystems are light saturated (Murata et al., 2007). Under high collimated light conditions, chloroplasts in leaves move to periclinal walls, and this might lead to decreased photoinhibition due to shading of other chloroplasts (Gorton et al., 1999). Under diffuse light, chloroplast movement to the periclinal walls is not complete (Williams et al., 2003) and thus distributed more randomly, which could lead to less effective self-shading and photoprotection (Brodersen et al., 2008).

The balance between photosynthesis and respiration and therefore, light use efficiency in benthic phototrophic systems is also influenced by the thickness of the diffusive and thermal boundary layers (Jørgensen and Des Marais, 1990; Jimenez et al., 2011; Brodersen et al., 2014). The diffusive boundary layer (DBL) is a thin water layer over submerged objects through which molecular diffusion is the dominant transport mechanism controlling the exchange of dissolved gases (e.g., $\mathrm{O}_{2}$ and $\mathrm{CO}_{2}$ ) and solutes with the ambient water (Jørgensen and Des Marais, 1990; Shashar et al., 1996). The DBL can thus impose a major control on respiration and photosynthesis in aquatic environments. Dissipation of absorbed solar radiation as heat drives an increase in surface temperature that is counterbalanced by heat transfer to the surrounding water via a thermal boundary layer (TBL), where convection dominates the transport of heat and the surface warming increases linearly with the incident irradiance (Jimenez et al., 2008). Heat and mass transfer phenomena through boundary layers are therefore important processes when considering rates of photosynthesis and radiative energy budgets.

In the present study, we present the first radiative energy budget of a heterogeneous coral reef sediment and compare it with the energy budget of a compact photosynthetic biofilm on a coastal sediment. We investigate how diffuse and collimated light fields with identical levels of incident irradiance affect the 
radiative energy budget of the two microphytobenthic systems. Our analysis is based on a modified experimental approach first described by Al-Najjar et al. (2010).

\section{MATERIALS AND METHODS Sample Sites and Collection}

Coral reef sediment was sampled in April 2012 from a sheltered pseudo-lagoon ("Shark Bay") (Werner et al., 2006) on the reef flat surrounding Heron Island $\left(151^{\circ} 55^{\prime} \mathrm{E}, 23^{\circ} 26^{\prime} \mathrm{S}\right)$ that is located on the southern boundary of the Great Barrier Reef, Australia. Maximal incident solar photon irradiance at the sediment surface of the shallow reef flat during calm mid-day low tides is $\sim 1,500$ 2,000 $\mu$ mol photons $\mathrm{m}^{-2} \mathrm{~s}^{-1}$ (Jimenez et al., 2012; Wangpraseurt et al., 2014b). The coral sediment (CS) was mainly composed of bright, semi-fine grained particles (mostly in the 200-500 $\mu \mathrm{m}$ size fraction) of deposited $\mathrm{CaCO}_{3}$ from decomposed corals and other calcifying reef organisms. Diatoms, dinoflagellates, and cyanobacteria were found as dispersed aggregates in the sediment pore space along with amorphic organic material (detritus) throughout the upper few mm of the sediment (Figure S1).

The biofilm (BF) originated from a shallow sand bar at Aggersund, Limfjorden (Denmark) experiencing maximum summer photon irradiance of 1,000-1,500 $\mu \mathrm{mol}$ photons $\mathrm{m}^{-2}$ $\mathrm{s}^{-1}$. The biofilm was comprised of a $\sim 1 \mathrm{~mm}$ thick smooth layer of photosynthetically active filamentous cyanobacteria and microalgae (Microcholeus chtonoplastes, Oscillatoria spp., and pennate diatoms) embedded in exopolymers on top of finegrained (125-250 $\mu \mathrm{m})$ dark sulfidic sandy sediment (Lassen et al., 1992b; Nielsen et al., 2015).

Coral reefs are usually considered oligotrophic but around Heron Island $\mathrm{NH}_{3}$ and $\mathrm{PO}_{4}$ concentrations of $\sim 0.3$ and $\sim 0.1 \mathrm{mg}$ $\mathrm{L}^{-1}$ (corresponding to $\sim 17 \mu \mathrm{mol} \mathrm{L}{ }^{-1} \mathrm{NH}_{3}$ and $\sim 1 \mu \mathrm{mol} \mathrm{L}^{-1}$ $\mathrm{PO}_{4}$ ) have been found (Smith and Johnson, 1995), which is lower but in the same order as what is found in Danish waters (see e.g., Figure 16.1 in Henriksen et al. (2001)). In our experiments, we used a recirculating system containing $20 \mathrm{~L}$ of seawater (see below) that was changed daily. We therefore do not estimate that nutrient concentrations had a large impact on production between the two systems.

The porosity of the coral sediment and biofilm, $\phi$, was 0.78 and 0.80 , respectively, as determined from the weight loss of wet sediment (known initial volume and weight) after drying at $60^{\circ} \mathrm{C}$ until a constant weight was reached:

$$
\phi=\frac{\frac{M_{W}}{D_{W}}}{\frac{M_{W}}{D_{W}}+\frac{M_{S}}{D_{S}}}
$$

where $M_{W}$ is the weight of water, $D_{W}$ is the density of water, $M_{S}$ is the weight of sediment/biofilm, and $D_{S}$ is the sediment/biofilm density.

\section{Coral Sediment Samples}

The CS samples were collected with Perspex corers (inner diameter $5.3 \mathrm{~cm}$ ), and were maintained under a continuous flow of aerated seawater at ambient temperature and salinity $\left(26^{\circ} \mathrm{C}\right.$ and $\left.S=35\right)$ under a natural solar light regime for $\sim 24 \mathrm{~h}$ prior to further handling at the Heron Island Research Station (HIRS), Australia. Sediment cores were then mounted in a custom-made flow-chamber flushed with aerated seawater $\left(26^{\circ} \mathrm{C}\right.$ and $\left.S=35\right)$ for another $24 \mathrm{~h}$ prior to measurements. The flow-chamber (interior dimensions: $25 \times 8 \times 8 \mathrm{~cm}$ ) had a honeycomb baffle between the water inlet and the sample, ensuring a stable laminar flow (see more details in Lichtenberg et al., 2016). During the acclimation time in the flow-chamber, the sediment cores were kept under a downwelling photon irradiance of $\sim 1,000 \mu \mathrm{mol}$ photons $\mathrm{m}^{-2} \mathrm{~s}^{-1}$ provided by a fiberoptic tungsten halogen lamp equipped with a collimating lens (KL2500-LCD, Schott GmbH, Germany). Before measurement at each experimental irradiance, the coral sediment core was illuminated for at least $45 \mathrm{~min}$ to ensure steady state $\mathrm{O}_{2}$ and temperature conditions; as confirmed from repeated microprofile measurements. Throughout measurements, the flow-chamber was flushed with a stable laminar flow $\left(\sim 0.5 \mathrm{~cm} \mathrm{~s}^{-1}\right)$ of filtered aerated seawater over the sediment surface as generated by a Fluval U1 pump submerged in a $20 \mathrm{~L}$ thermostated aquarium $\left(26^{\circ} \mathrm{C}\right.$ and $\left.S=35\right)$ and connected with tubing to the flowchamber.

\section{Biofilm Samples}

The BF samples were collected and contained in small rectangular plastic trays $(7 \times 2 \times 5 \mathrm{~cm})$ with the upper surface exposed and flush with the upper edge of the tray wall. After collection, the samples were kept humid and under a 12:12 h light-dark regime $\left(\sim 100 \mu \mathrm{mol}\right.$ photons $\mathrm{m}^{-2}$ $\left.\mathrm{s}^{-1}\right)$ in a thermostated room $\left(16-18^{\circ} \mathrm{C}\right)$. The biofilm surface appeared dark green-brownish due to predominance of dense communities of cyanobacteria and diatoms (Lassen et al., 1992b). Prior to measurements, a sample tray was placed for 2 days in a flow-chamber flushed with $0.2 \mu \mathrm{m}$ filtered aerated seawater $\left(21^{\circ} \mathrm{C}, S=30\right)$ under a downwelling photon irradiance of $\sim 500$ $\mu \mathrm{mol}$ photons $\mathrm{m}^{-2} \mathrm{~s}^{-1}$. During measurements, a stable laminar flow $\left(\sim 0.5 \mathrm{~cm} \mathrm{~s}^{-1}\right)$ over the biofilm surface was maintained by a water pump (Fluval U1, Hagen GmbH, Germany) immersed in a $20 \mathrm{~L}$ aquarium with filtered aerated seawater $\left(21^{\circ} \mathrm{C}, S=30\right)$ and connected with tubing to the flow-chamber.

\section{Experimental Setup}

Illumination was provided by a fiber-optic tungsten halogen lamp equipped with a collimating lens (KL-2500 LCD, Schott, Germany) positioned vertically above the flow-chamber. A spectrum of the used halogen lamp can be found in the Suppl. Info. in Lichtenberg et al. (2016) and is compared to typical solar spectrum measured on Heron Island reef flat in the Suppl. Info. in Wangpraseurt et al. (2014a), who found no major spectral effects on gross photosynthesis measurements. The intensity of the lamp could be controlled without spectral distortion by a built-in filter wheel with pinholes of various sizes. The downwelling photon irradiance of photosynthetically active radiation (PAR, 400-700 $\mathrm{nm}), \mathrm{E}_{\mathrm{d}}(\mathrm{PAR})$, (see definitions of abbreviations in Appendix) was measured with a calibrated irradiance meter (ULM-500, Walz GmbH, Germany) equipped with a cosine collector (LI192S, LiCor, USA). Defined experimental irradiances (0, 50, 100, 200, 500, and 1,000 $\mu \mathrm{mol}$ photons $\mathrm{m}^{-2} \mathrm{~s}^{-1}$ ) were achieved by 
adjusting the aperture on the fiber-optic lamp. The downwelling spectral irradiance at the above-mentioned levels was also measured in radiometric energy units (in $\mathrm{W} \mathrm{m}^{-2} \mathrm{~nm}^{-1}$ ) with a calibrated spectroradiometer (Jaz, Ocean Optics, USA).

Collimated light was achieved by attaching a collimating lens to the fiber cable of the lamp. Diffuse light was achieved by inserting a TRIMMS diffuser (Transparent Refractive Index Matched Microparticles; Smith et al., 2003) between the collimator and the sample followed by lamp adjustment to achieve the same absolute levels of downwelling irradiance on the biofilm/sediment surface in collimated and diffuse light treatments.

\section{Microscale Measurements of $\mathrm{O}_{2}$ and Temperature}

Oxygen concentrations were measured with a Clark-type $\mathrm{O}_{2}$ microsensor (tip diameter $\sim 25 \mu \mathrm{m}$; OX-25, Unisense A/S, Aarhus, Denmark) with a fast response time $(<0.5 \mathrm{~s})$ and a low stirring sensitivity (<1-2\%; Revsbech, 1989). The microsensor was connected to a pA-meter (Unisense A/S, Aarhus, Denmark) and was linearly calibrated at experimental temperature and salinity from measurements in the aerated seawater in the freeflowing part of the flow-chamber and in anoxic layers of the sediment.

Temperature measurements were performed with a thermocouple microsensor (tip diameter $\sim 50 \mu \mathrm{m}$; T50, Unisense A/S, Aarhus, Denmark) connected to a thermocouple meter (Unisense A/S, Aarhus, Denmark). The temperature microsensors were linearly calibrated against readings of a high precision thermometer (Testo 110, Testo AG, Germany; accuracy $\pm 0.2^{\circ} \mathrm{C}$ ) in seawater at different temperatures. Analogue outputs from the temperature and $\mathrm{O}_{2}$ microsensor meters were connected to an A/D converter (DCR-16, Pyroscience GmbH, Germany), which was connected to a PC. All microsensors were mounted in a PC-interfaced motorized micromanipulator (MU-1, PyroScience GmbH, Germany) controlled by dedicated data acquisition and positioning software (ProFix, Pyroscience, Germany). The micromanipulator was oriented in a $45^{\circ}$ angle relative to the vertically incident light to avoid selfshading, especially in the light measurements. Depth profiles of temperature and $\mathrm{O}_{2}$ concentration were measured in vertical steps of $100 \mu \mathrm{m}$. Before profiling, the microsensor tips were manually positioned on the sample surface to define the $z=$ 0 position, determined from visual detection through a stereo microscope. The precisions of this approach is about \pm the average grain size of the sediments, i.e., 125-500 $\mu \mathrm{m}$.

The local volumetric rates of gross photosynthesis $\left(\mathrm{P}_{\mathrm{G}}(\mathrm{z})\right.$; in units of nmol $\mathrm{O}_{2} \mathrm{~cm}^{-3} \mathrm{~s}^{-1}$ ) were measured with $\mathrm{O}_{2}$ microsensors using the light-dark shift method (Revsbech and Jørgensen, 1983). Volumetric rates were measured in vertical steps of $100 \mu \mathrm{m}$ throughout the sediment until no photosynthetic activity in the given depth was detected. The immediate $\mathrm{O}_{2}$ depletion rate upon brief (2-4 s) darkening equalled the local rate of photosynthesis just prior to darkening; while no response in the $\mathrm{O}_{2}$ signal upon darkening indicated a zero rate of photosynthesis. Areal rates of gross photosynthesis (in nmol $\mathrm{O}_{2}$ $\mathrm{cm}^{-2} \mathrm{~s}^{-1}$ ) were calculated by depth integration over the euphotic zone with respect to the measuring interval used in the depth profile measurement of $\mathrm{P}_{\mathrm{G}}(\mathrm{z})$, similar to Al-Najjar et al. (2010, 2012):

$$
P G=\Delta z \cdot \sum P_{G}(z)
$$

\section{Temperature and $\mathrm{O}_{2}$ Calculation}

The net upward flux of $\mathrm{O}_{2}$ from the photic zone of the sediments into the overlaying seawater was calculated (in $\mathrm{nmol} \mathrm{O}_{2} \mathrm{~cm}^{-2}$ $\mathrm{s}^{-1}$ ) from measured steady-state $\mathrm{O}_{2}$ concentration profiles using Fick's first law of diffusion:

$$
J_{N P P \uparrow}=-D_{0} \frac{\partial C}{\partial z}
$$

where $\mathrm{D}_{0}$ is the diffusion coefficient of $\mathrm{O}_{2}$ in seawater at experimental temperature and salinity and $\frac{\partial C}{\partial z}$ is the linear $\mathrm{O}_{2}$ concentration gradient in the DBL.

The downward $\mathrm{O}_{2}$ flux from the photic zone of the sediments to the aphotic part of the sediment/biofilm was calculated in a similar manner as:

$$
J_{N P P \downarrow}=-\phi D_{0} \frac{\partial C}{\partial z}
$$

The total flux of $\mathrm{O}_{2}$ out of the photic zone, i.e., the total net photosynthesis in the photic zone (NPP), was subsequently calculated as the difference between the upward and downward $\mathrm{O}_{2}$ flux (Kühl et al., 1996).

To calculate the radiative energy conserved via photosynthesis (JPs; in $\mathrm{J} \mathrm{m}^{-2} \mathrm{~s}^{-1}$ ) we multiplied the areal gross photosynthesis, GPP, with the Gibbs free energy formed in the light-dependent reactions, where $\mathrm{O}_{2}$ is formed by splitting water, which gains (including the formation of ATP) a Gibbs free energy of $\mathrm{E}_{\mathrm{G}}=$ $482.9 \mathrm{~kJ}\left(\mathrm{~mol} \mathrm{O}_{2}\right)^{-1}$ (Thauer et al., 1977).

$$
J_{P S}=J_{G P P} E_{G}
$$

The amount of the absorbed light energy that was not photochemically conserved was dissipated as heat resulting in a local increase of the sediment/biofilm temperature relatively to the ambient seawater and thereby leading to the establishment of a TBL. The heat dissipation, i.e., the heat flux (in $\mathrm{J} \mathrm{m}^{-2} \mathrm{~s}^{-1}$ ) from the sediment/biofilm into the water column was calculated by Fourier's law of conduction:

$$
J_{H \uparrow}=k \frac{\partial T}{\partial z}
$$

where $k$ is the thermal conductivity in seawater $\left(0.6 \mathrm{~W} \mathrm{~m}^{-1} \mathrm{~K}^{-1}\right)$ and $d T / d z$ is the measured linear temperature gradient in the TBL (Jimenez et al., 2008). The heat flux from the photic zone into the aphotic sediment/biofilm, $\mathrm{J}_{H \downarrow}$, was calculated as in Equation (6) but with the thermal conductivity constant of the sediment, $k(b)$, which was estimated as:

$$
k(b)=k_{s}^{(1-\phi)} k_{f}^{\phi}
$$


where $k_{\mathrm{s}}$ is the carbonate thermal conductivity $\left(3.1 \mathrm{~W} \mathrm{~m}^{-1}\right.$ $\mathrm{K}^{-1}$; Clauser and Huenges, 1995), $k_{\mathrm{f}}$ is the seawater thermal conductivity, and $\phi$ is the porosity of the sediment (Lovell, 1985).

The total heat flux, was used as an estimate of the total heat dissipation in the photic zone and was calculated as: $J_{H}=J_{H \uparrow}-J_{H \downarrow}$.

\section{Microscale Light Measurements}

Spectral photon scalar irradiance was measured in units of counts $\mathrm{nm}^{-1}$ with a fiber-optic scalar irradiance microprobe [integrating sphere diameter $\sim 100 \mu \mathrm{m}$; (Lassen et al., 1992a)] connected to a fiber-optic spectrometer (USB2000, Ocean Optics, Dunedin, FL, USA). A black non-reflective light-well was used to record spectra of the downwelling photon scalar irradiance, $E_{d}(\lambda)$, (in units of counts $\mathrm{nm}^{-1}$ ) with the tip of the scalar irradiance microsensor positioned in the light path at the same distance from the light source as the sediment surface. Using identical light settings, the absolute downwelling irradiance, $E_{A B S}(\lambda)$ (in $\mathrm{W} \mathrm{m}^{-2}$ ) was also quantified with a calibrated spectroradiometer (Jaz-ULM, Ocean Optics, Dunedin, Florida, USA).

\section{Irradiance Calculations}

The spectral scalar irradiance, $E_{0}(\lambda)$, was measured in vertical steps of $0.1-0.2 \mathrm{~mm}$ in the sediment and was calculated as the fraction of the incident downwelling irradiance, i.e., $E_{0}(\lambda) / E_{d}(\lambda)$, and plotted as transmittance spectra in $\%$ of $E_{d}(\lambda)$. The relative measurements of scalar irradiance in different depths in the biofilm/sediment were converted to absolute scalar irradiance spectra in units of $\mathrm{W} \mathrm{m} \mathrm{m}^{-2} \mathrm{~nm}^{-1}$ as $E_{A B S}(\lambda)^{\times} E_{0}(\lambda) / E_{d}(\lambda)$. Absolute scalar irradiance spectra were converted to photon scalar irradiance spectra (in units of $\mu \mathrm{mol}$ photons $\mathrm{m}^{-2} \mathrm{~s}^{-1}$ $\mathrm{nm}^{-1}$ ) by using Planck's equation:

$$
E_{\lambda}=h \frac{c}{\lambda}
$$

where $E_{\lambda}$ is the energy of a photon with wavelength, $\lambda, h$ is Planck's constant $\left(6.626 \times 10^{-34} \mathrm{~W} \mathrm{~s}^{2}\right)$, and $c$ is the speed of light in vacuum (in $\mathrm{m} \mathrm{s}^{-1}$ ).

Spectral attenuation coefficients of scalar irradiance, $K_{0}(\lambda)$, were calculated as (Kühl, 2005):

$$
\mathrm{K}_{0}(\lambda)=-\ln \frac{\left(E_{0}(\lambda)_{1} / E_{0}(\lambda)_{2}\right)}{z_{2}-z_{1}}
$$

where $E_{0}(\lambda)_{1}$ and $E_{0}(\lambda)_{2}$ are the spectral scalar irradiances measured at depth $z_{1}$ and $z_{2}$, respectively.

Light attenuation was also calculated by integrating the spectral quantum irradiance over PAR $(420-700 \mathrm{~nm})$ yielding the PAR scalar irradiance $\left(E_{0}(P A R)\right.$, in $\mu$ mol photons $\mathrm{m}^{-2} \mathrm{~s}^{-1}$ ), i.e., the light energy available for oxygenic photosynthesis at each measurement depth. The diffuse attenuation coefficient of $E_{0}(P A R), K_{0}(P A R)$, was obtained by fitting the measured $E_{0}(P A R)$ $v s$. depth profiles with an exponential model:

$$
E_{0}(z)=E_{0}(0) e^{-K_{0}(P A R)(z-z(0))}
$$

\section{Reflectance Measurements}

The PAR irradiance reflectance (R) of the sediment/biofilm surface was calculated as

$$
R(P A R)=\int_{420}^{700} \frac{E_{u}(\lambda)}{E_{d}(\lambda)} d \lambda
$$

where $E_{u}(\lambda)$ is the upwelling irradiance at the sediment surface, here estimated as the diffuse backscattered spectral radiance measured at the sediment surface (Kühl, 2005) and $E_{d}(\lambda)$ is the downwelling irradiance estimated as the backscattered spectral radiance measured over a white reflectance standard (Spectralon; Labsphere, North Sutton, NH, USA); both measured with a fiber-optic field radiance microprobe (Jørgensen and Des Marais, 1988). The R(PAR) measurements assumed that the light backscattered from the sediment/biofilm surface was completely diffused (Kühl and Jørgensen, 1994).

\section{Absorbed Light Energy}

The absorbed light energy $\left(\mathrm{J}_{\mathrm{ABS}}\right.$; in $\mathrm{W} \mathrm{m} \mathrm{m}^{-2}=\mathrm{J} \mathrm{m}^{-2} \mathrm{~s}^{-1}$ ) in the sediment/biofilm was estimated by subtracting the downwelling and upwelling irradiance at the surface:

$$
J_{A B S}=\int_{420}^{700} E_{d}(\lambda)(1-R(\lambda)) d \lambda
$$

where $E_{d}(\lambda)$ and $R(\lambda)$ are the downwelling spectral irradiance and irradiance reflectance, respectively. This parameter is equivalent to the so-called vector irradiance, which is a measure of the net downwelling radiative energy flux.

\section{Energy Budget and Photosynthetic Efficiency Calculations}

A balanced radiative energy budget of the sediment/biofilm was calculated according to (Al-Najjar et al., 2010) with slight modifications (Figure 1) as:

$$
J_{A B S}=J_{H}+J_{P S}
$$

assuming that autofluorescence from the sediment/biofilm was negligible. Consequently, $\varepsilon_{P S}+\varepsilon_{H}=1$, where, $\varepsilon_{P S}$ and $\varepsilon_{H}$ represent the efficiency of photosynthetic energy conservation and heat dissipation, respectively, for a given absorbed light energy $J_{A B S}$ in the entire euphotic zone (Al-Najjar et al., 2010):

$$
\varepsilon_{P S}=\frac{J_{P S}\left(J_{A B S}\right)}{J_{A B S}} \text { and } \varepsilon_{H}=\frac{J_{H}\left(J_{A B S}\right)}{J_{A B S}}
$$

Areal gross photosynthesis rates as a function of $J_{A B S}$, were fitted with the saturated exponential model (Webb et al., 1974) to estimate the maximum conserved energy flux by photosynthesis $\left(J_{P S, \text { max }}\right)\left(\right.$ in $\left.\mathrm{J} \mathrm{m}^{-2} \mathrm{~s}^{-1}\right)$ :

$$
J_{P S}\left(J_{A B S}\right)=J_{P S, \max }\left(1-e^{-J_{A B S} / E_{k}}\right)
$$

This yielded an estimate of the maximum photochemically conserved energy flux $J_{P S, \max }$. The respective efficiencies 


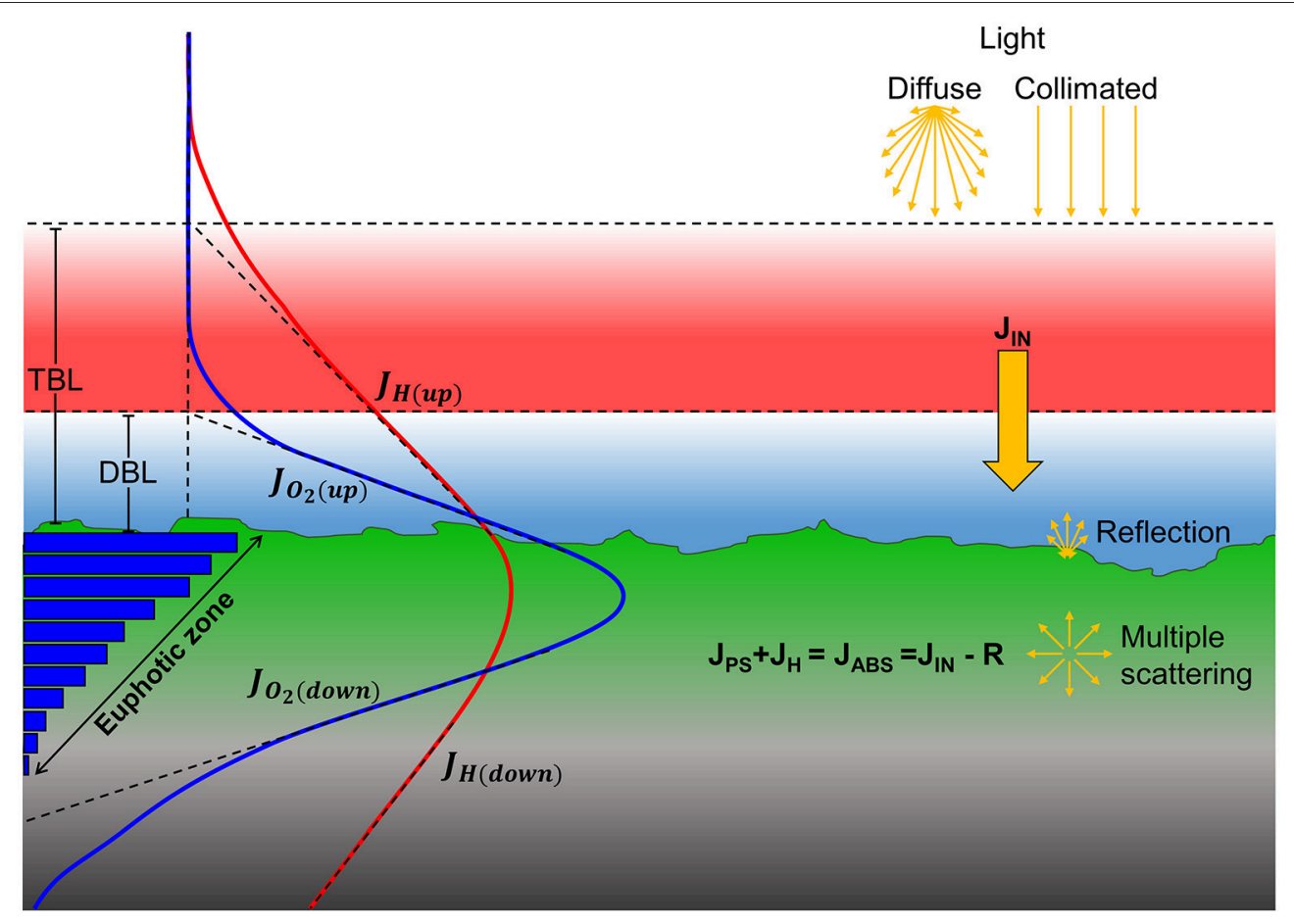

FIGURE 1 | Major pathways of light energy conversion and dissipation in biofilm and coral sediment. Incident irradiance was either diffuse or collimated (top yellow arrows) and supplied the sediments with the incoming energy flux, $J_{\mathbb{N}}$ (solid yellow arrow). A fraction of the incoming light energy was reflected from the surface and thereby not a part of the absorbed light energy $\left(\mathrm{J}_{\mathrm{ABS}}\right)$. Through multiple scattering by biotic and abiotic components in the biofilm/sediment, the light field becomes increasingly diffuse with depth. The absorbed light energy is either photochemically conserved in photosynthesis (JPS) in the photic zone or dissipated as heat $\left(\mathrm{J}_{H}\right)$ via radiative energy transfer and non-photochemical quenching leading to local heating in the biofilm/sediment (red line). Gross photosynthesis (blue bars) is dependent on light and is thus higher near the surface which drives a production of $\mathrm{O}_{2}$ (blue line) that exceeds the consumption via respiration and leads to the formation of a diffusive boundary layer (DBL). The surplus of $\mathrm{O}_{2}$, i.e., the net photosynthesis, can be calculated as the difference between the upwards $\left(\mathrm{J}_{\mathrm{O}_{2}}\left(\mathrm{Up}_{\mathrm{p}}\right)\right.$ ), and downwards $\left(\mathrm{J}_{2}(\right.$ Down $)$ flux of $\mathrm{O}_{2}$ from the photic zone. Similarly, the fraction of the absorbed energy that is dissipated as heat can be calculated as the difference between upwards $\left(J_{H(U p)}\right)$ and downwards $\left(J_{H(D o w n)}\right)$ heat flux through the thermal boundary layer (TBL) into the overlaying water and into the aphotic sediment/biofilm layer, respectively.

under light-limiting conditions, i.e., for $J_{A B S} \rightarrow 0$, were then calculated as:

$$
\varepsilon_{P S, \text { max }}=\frac{J_{P S, \text { max }}}{E_{k}} \text { and } \varepsilon_{H, \text { min }}=1-\varepsilon_{P S, \text { max }}
$$

where $E_{k}$ is the photochemical light acclimation index, i.e., the irradiance at the onset of photosynthetic saturation, calculated as $E_{k}=J_{P S, \max } / \alpha$, where $\alpha$ is the initial slope of the fitted photosynthesis vs. JABS curve.

\section{RESULTS}

\section{Light Environment}

At all incident irradiances, the photon scalar irradiance, $\mathrm{E}_{0}(\mathrm{PAR})$, decreased with increasing sediment depth (Figure 2). Light attenuation was strongly enhanced around wavelengths 625 and $670 \mathrm{~nm}$, corresponding to absorption maxima of phycocyanin and $\mathrm{Chl} a$, respectively (Figure 3). Surface reflection from the biofilm surface was on average 1.8 and $1.7 \%$ of the incident PAR under diffuse and collimated light, respectively, while it was $>15$ times higher in the coral sediment, i.e., 30.2 and
28.1\% for diffuse and collimated light, respectively. Reflection did not change with increasing irradiance (Figure S2). The profiles of scalar irradiance showed non-uniform attenuation with depth and could be influenced by local enhancement of photon pathlength (Kühl and Jørgensen, 1994; Kühl et al., 1997) in the uppermost layers (Figure 2). At the highest incident photon irradiances (500 and 1,000 $\mu \mathrm{mol}$ photons $\mathrm{m}^{-2} \mathrm{~s}^{-1}$ ), the exponential attenuation of collimated light within the biofilm was observed below $0.2 \mathrm{~mm}$, whereas diffuse light was attenuated exponentially from the biofilm surface under all investigated irradiance levels (Figure 2). In the coral sediment, the exponential attenuation occurred deeper (below 0.5-0.7 $\mathrm{mm}$ ) due to enhanced scattering, redistribution and trapping of photons in the upper sediment layers (Figure 2). In the biofilm, PAR attenuation was stronger in the top layer than in the bottom layer both for diffuse and collimated light (Figure 2). Additionally, attenuation of collimated light in the top layer was stronger than for diffuse light at all irradiances except $1,000 \mu \mathrm{mol}$ photons $\mathrm{m}^{-2} \mathrm{~s}^{-1}$, whereas light attenuation in the lower sediment dominated layers was similar for diffuse and collimated incident light. In the coral sediment no distinct 

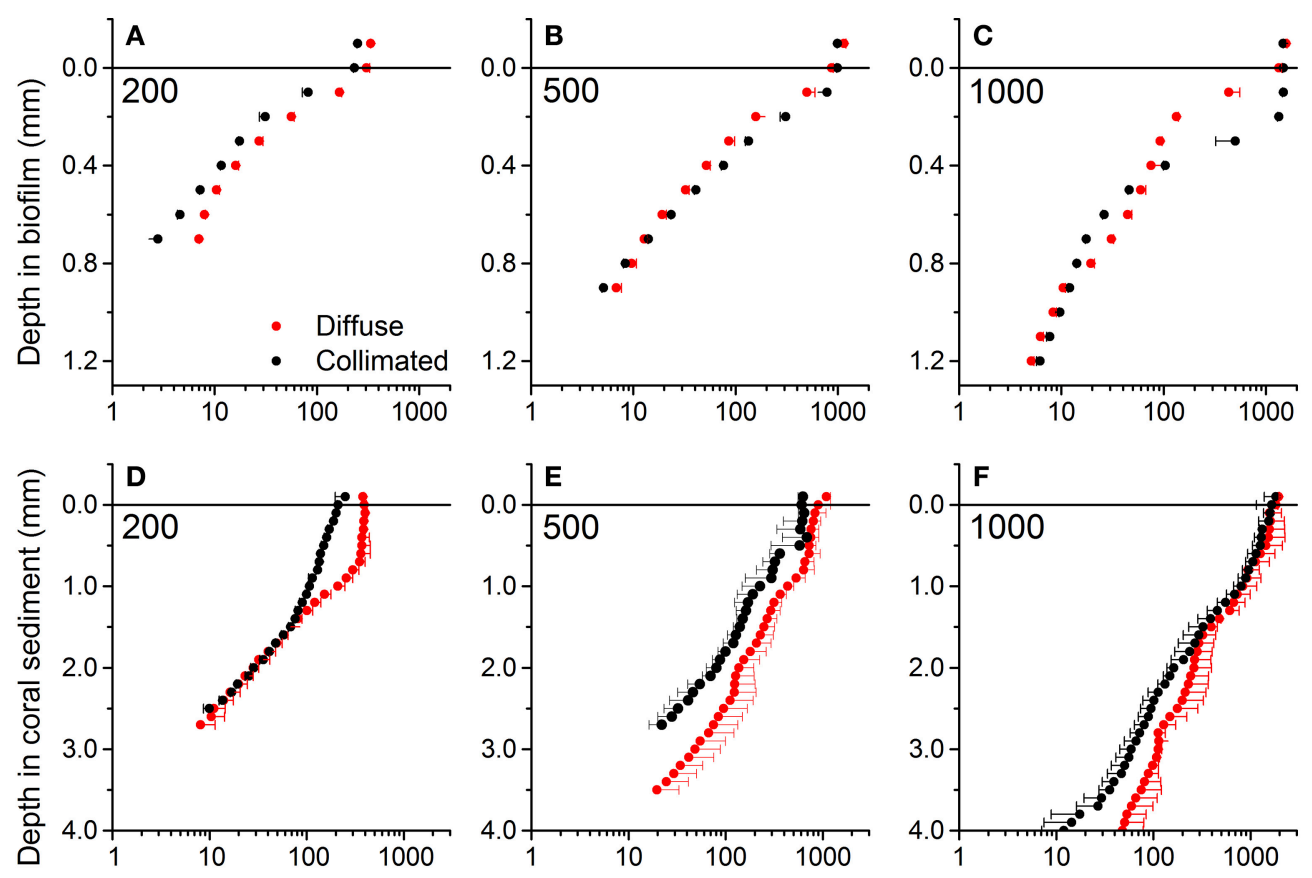

Photon scalar irradiance $\left(\mu \mathrm{mol}\right.$ photons $\left.\mathrm{m}^{-2} \mathrm{~s}^{-1}\right)$

FIGURE 2 | Vertical profiles of photon scalar irradiance (PAR, 400-700 nm) in the biofilm (A-C) and coral sediment (D-F) under different incident photon irradiance (numbers in panels) of collimated (black symbols) and diffuse (red symbols) light. In the biofilm the light attenuation coefficient ( $\alpha$ ) was estimated in both the upper $(0-0.4 \mathrm{~mm})$ and lower $(0.5-1.2 \mathrm{~mm})$ layer while $\alpha$ was estimated for the entire exponential part of the curve in the coral sediment $\left(R^{2}>0.95 \mathrm{in}\right.$ all cases). Data points show averages \pm 1 S.D. (note that for clarity, only plus S.D. is shown for diffuse light and minus S.D. for collimated light; $n=3$ ).

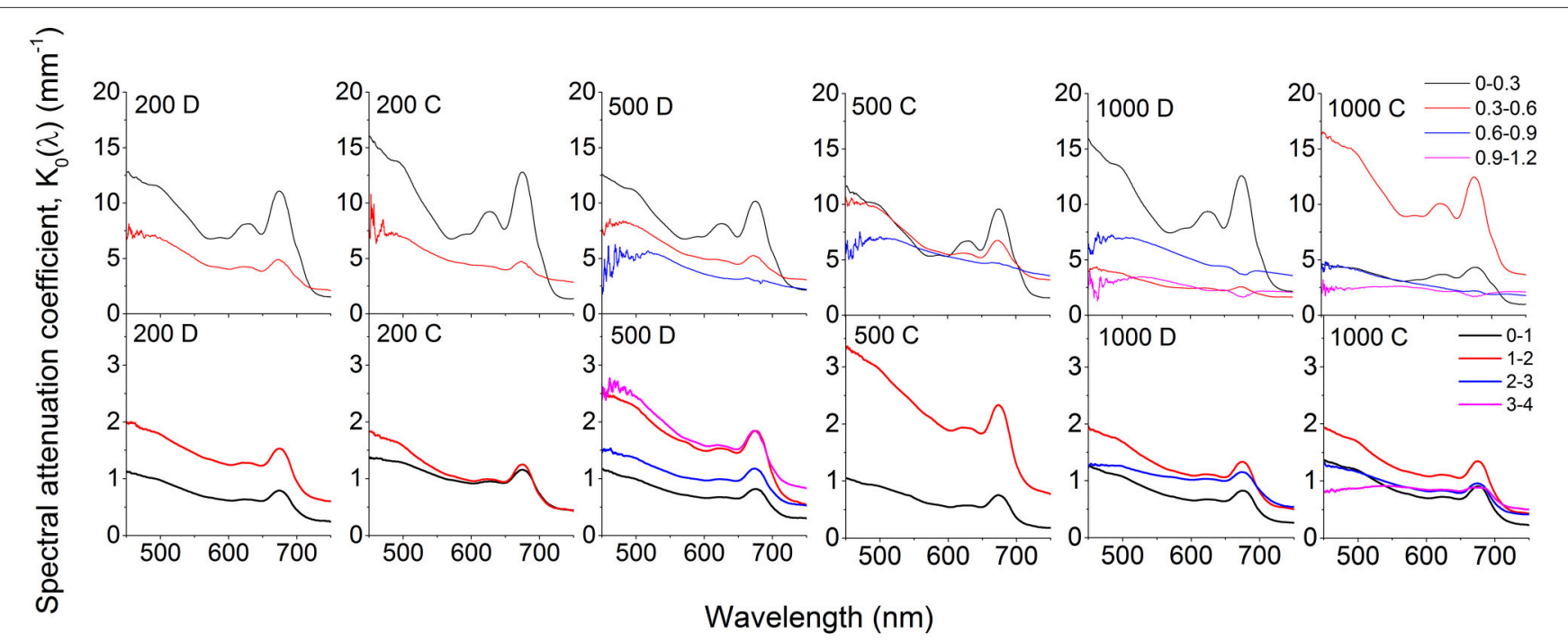

FIGURE 3 | Spectral attenuation coefficients, $\mathbf{K}_{\mathbf{0}}(\lambda)$ (PAR) of photon scalar irradiance calculated over $300 \mu \mathrm{m}$ (biofilm; upper panels) and $1,000 \mu \mathrm{m}$ (coral sediment; lower panels) depth intervals. Numbers in panels indicate incident photon irradiance in $\mu$ mol photons $\mathrm{m}^{-2} \mathrm{~s}^{-1}$, while the letters $\mathrm{C}$ and $\mathrm{D}$ denote collimated and diffuse incident light, respectively. Curves represent averages ( $n=3 ;$ S.D. not shown for clarity).

differences in light attenuation was observed between topand bottom layers other than a deeper onset of exponential attenuation $(0.5-0.7 \mathrm{~mm})$. The top layer of the biofilm showed $\sim 10$ times stronger light attenuation than the coral sediment with average PAR attenuation coefficient of $\alpha=9.52$ and $\alpha$ $=10.54 \mathrm{~mm}^{-1}$ for diffuse and collimated light, respectively, compared to $\alpha=1.18 \mathrm{~mm}^{-1}$ in the coral sediment (both light types). 
In both sediments, attenuation of light corresponded to absorption maxima of Chl $a$ (440 and $670 \mathrm{~nm}$ ) and phycocyanin (620 nm; Figure 3). A third attenuation maximum was observed around $575 \mathrm{~nm}$ indicative of phycoerythrin, commonly found in cyanobacteria (Colyer et al., 2005). In the biofilm, attenuation of visible light was strongest in the top $0.3 \mathrm{~mm}$ of the biofilm, except under the highest collimated irradiance $\left(1000 \mu \mathrm{mol}\right.$ photons $\mathrm{m}^{-2}$ $\mathrm{s}^{-1}$ ), where the strongest attenuation occurred over the 0.3-0.6 $\mathrm{mm}$ zone (Figure 3). Below $0.6 \mathrm{~mm}$, the enhanced attenuation around wavelengths 575, 625, and $670 \mathrm{~nm}$ decreased and the attenuation of light in the PAR region became more uniform in the underlying layers (Figure 3). Again, attenuation of collimated light was slightly higher than diffuse light.

In the coral sediment, the highest light attenuation was 1-2 mm below the sediment surface $\left(\sim 1.6 \mathrm{~mm}^{-1}\right.$ at $670 \mathrm{~nm}$ at all incident irradiances) while the lowest attenuation was found in the upper $0-1 \mathrm{~mm}$, consistent with the scalar irradiance profiles (Figures 2, 3).

\section{Temperature and $\mathrm{O}_{2}$ Microenvironment}

In the biofilm, a $\sim 0.8 \mathrm{~mm}$ thick diffusive boundary layer (DBL) developed between the biofilm and the surrounding water (Figures 1, 4). In dark, $\mathrm{O}_{2}$ was depleted within the upper $1.5 \mathrm{~mm}$ and the areal dark respiration rate was calculated to $0.039 \mathrm{nmol} \mathrm{O}_{2} \mathrm{~cm}^{-2} \mathrm{~s}^{-1}$. The fluxes of $\mathrm{O}_{2}$ increased with irradiance until saturation was reached at a downwelling photon irradiance of $\sim 100 \mu \mathrm{mol}$ photons $\mathrm{m}^{-2} \mathrm{~s}^{-1}$, where the top of the biofilm experienced $\mathrm{O}_{2}$ concentrations $>450 \%$ of air saturation (Figure 4). The $\mathrm{O}_{2}$ concentration profiles for diffuse and collimated light were similar, although $\mathrm{O}_{2}$ penetrated deeper under diffuse light, especially at the highest photon irradiances (500 and 1,000 $\mu \mathrm{mol}$ photons $\mathrm{m}^{-2} \mathrm{~s}^{-1}$; Figure 4). The coral sediment had a $\sim 1-1.4 \mathrm{~mm}$ thick DBL; dark respiration was similar to the biofilm $\left(0.037 \mathrm{nmol} \mathrm{O}_{2} \mathrm{~cm}^{-2} \mathrm{~s}^{-1}\right)$, while saturation of photosynthesis was reached at a higher downwelling photon irradiance of $\sim 200 \mu \mathrm{mol}$ photons $\mathrm{m}^{-2} \mathrm{~s}^{-1}$ (Figure 3). The similar dark respiratory $\mathrm{O}_{2}$ uptake in sediment and biofilm indicated that the combined respiration of autotrophic and heterotrophic organisms was of similar magnitude in the two systems. The more variable DBL thickness in the coral sediment varied independently of irradiance and was most likely a result of the heterogeneous surface topography (Figure 4). A detailed mapping of the DBL landscape was beyond the scope of this study but, we estimate that the mass transfer between the sediment and overlying water was not influenced by turbulences which would have been evident as non-linear concentration gradients between sediment surface and bulk water (Lichtenberg et al., 2017). At incident irradiances $>200 \mu \mathrm{mol}$ photons $\mathrm{m}^{-2} \mathrm{~s}^{-1}$ the $\mathrm{O}_{2}$ productive zone was stratified under both diffuse and collimated light, with an $\mathrm{O}_{2}$ concentration maximum of $\sim 600 \%$ air saturation $\sim 1.7 \mathrm{~mm}$ below the sediment surface (Figure 4). Photosynthesis was apparently distributed in two major layers, a $\sim 0.5 \mathrm{~mm}$ thick layer at the sediment surface, and a $\sim 1$ $\mathrm{mm}$ thick layer peaking $2 \mathrm{~mm}$ below the sediment surface (Figure 4 and Figure S3). The $\mathrm{O}_{2}$ concentration profiles for diffuse and collimated light were similar at low to moderate irradiance, then showed a deeper $\mathrm{O}_{2}$ penetration depth under diffuse light at incident irradiance $>500 \mu \mathrm{mol}$ photons $\mathrm{m}^{-2}$ $\mathrm{s}^{-1}$ in comparison to $\mathrm{O}_{2}$ profiles measured under collimated light (Figure 4). The $\mathrm{O}_{2}$ profiles in the coral sediment showed high standard deviations, possibly due to a more patchy distribution of the photosynthetic organisms within the sediment and overall variability in the sediment grain size and surface topography.

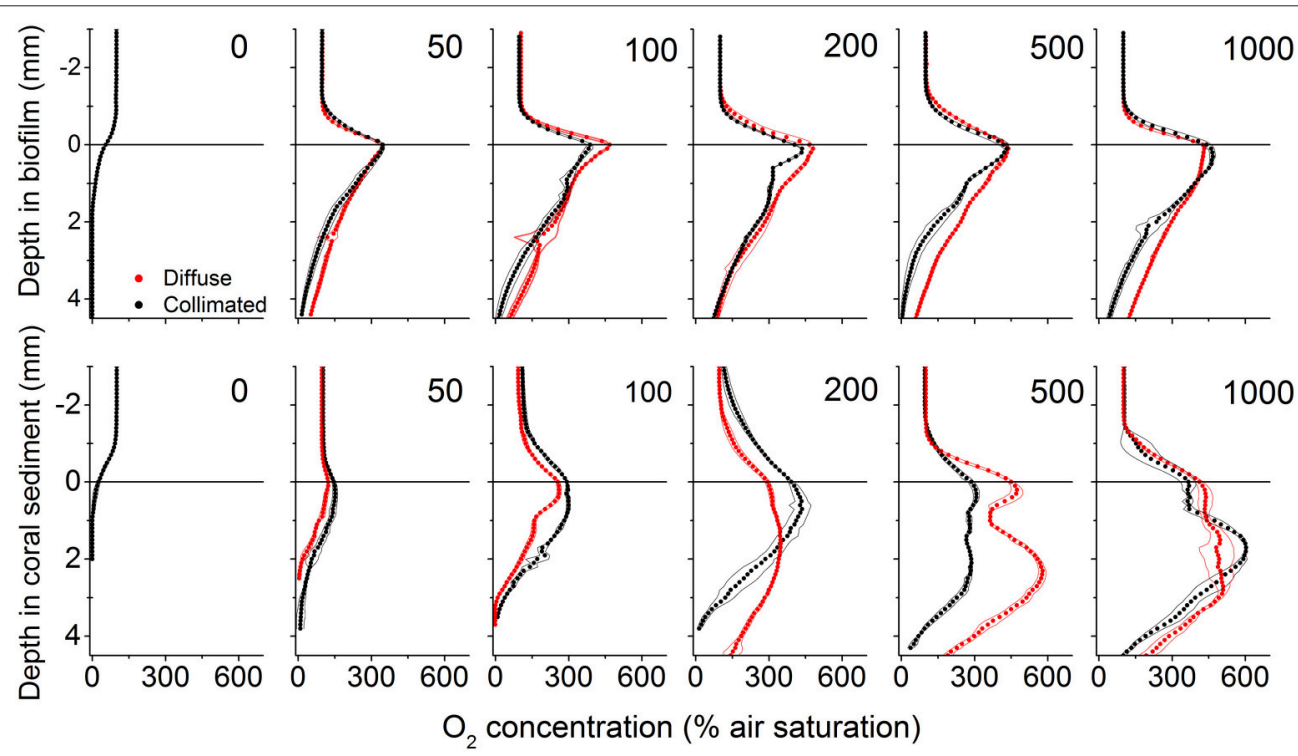

FIGURE 4 | Vertical microprofiles of $\mathrm{O}_{2}$ concentration in biofilm (upper panel) and coral sediment (lower panel). Red and black symbols represent measurements under diffuse and collimated light, respectively, while numbers in panels denote downwelling photon irradiance in $\mu \mathrm{mol}^{\mathrm{p}}$ photons $\mathrm{m}^{-2} \mathrm{~s}^{-1}$. The line in y $=0$ indicates the biofilm/sediment surface. Symbols represent mean values, while dashed lines represent $\pm 1 S . D$. $(n=3$ ). 
In both biofilm and coral sediment, the surface temperature increased relative to the overlaying seawater with increasing irradiance. The local heating was dissipated by heat transfer over a $\sim 3 \mathrm{~mm}$ thick TBL into the overlaying seawater and into deeper sediment layers (Figures 5, 6). Robust measurements of biofilm/sediment heating could only be obtained at incident photon irradiances of $\geq 200 \mu \mathrm{mol}$ photons $\mathrm{m}^{-2} \mathrm{~s}^{-1}(\geq 500$ $\mu$ mol photons $\mathrm{m}^{-2} \mathrm{~s}^{-1}$ for the coral sediment under collimated light). At the highest irradiance $\left(1,000 \mu \mathrm{mol}\right.$ photons $\mathrm{m}^{-2}$ $\mathrm{s}^{-1}$ ), the biofilm surface was $0.51 \pm 0.036$ and $0.41 \pm 0.008^{\circ} \mathrm{C}$ warmer than the overlaying water, while the coral sediment surface was $0.53 \pm 0.031$ and $0.48 \pm 0.040^{\circ} \mathrm{C}$ warmer than the surrounding water for diffuse and collimated light, respectively. Similar temperature profiles were observed between collimated and diffuse light, although a slightly enhanced surface heating and thus a higher efflux of heat was observed under diffuse light (Figure 5). Comparing the slope of the surface warming vs. vector irradiance under diffuse and collimated light, respectively, diffuse light had a greater impact on surface warming by 30 and $27 \%$ in the biofilm and in the coral sediment, respectively (Figure 6).

\section{Photosynthesis}

Maximal volume-specific gross photosynthesis rates of the biofilm ranged between 7.0 and $8.7 \mathrm{nmol} \mathrm{O}_{2} \mathrm{~cm}^{-3} \mathrm{~s}^{-1}$ (collimated and diffuse light, respectively) under low irradiance (50-200 $\mu$ mol photons $\mathrm{m}^{-2} \mathrm{~s}^{-1}$ ), while rates decreased at photon

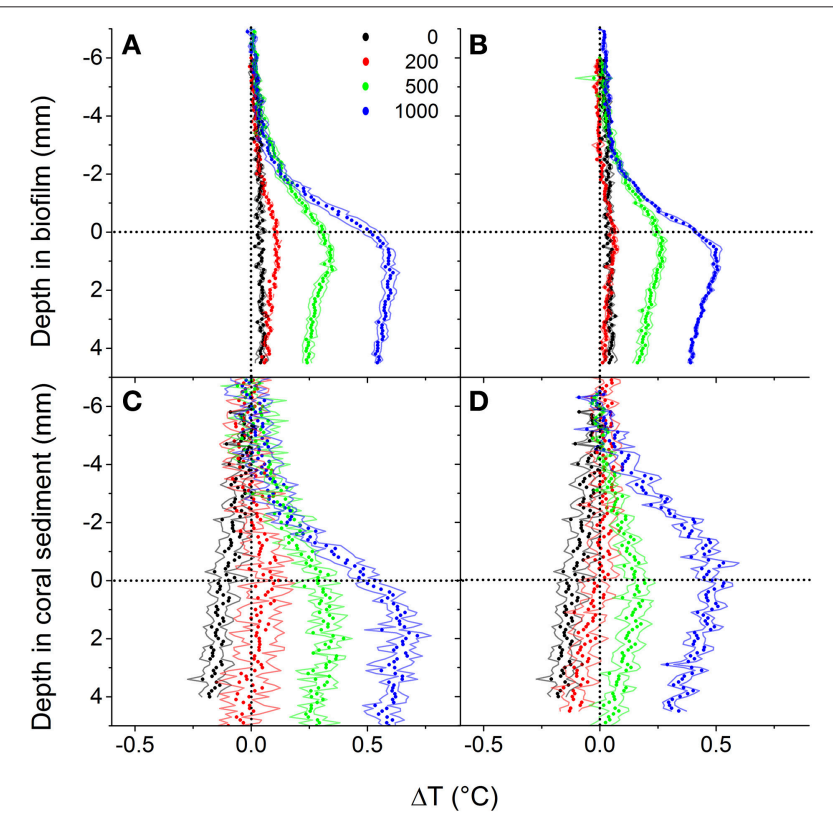

FIGURE 5 | Vertical depth profiles of temperature change, $\Delta \mathrm{T}$ (in ${ }^{\circ} \mathrm{C}$ ) measured in biofilm (upper panels) and coral sediment (lower panel) at downwelling photon irradiances of $0,200,500$, and 1,000 $\mu \mathrm{mol}$ photons $\mathbf{~ m}^{-2} \mathbf{s}^{-1}$ under collimated (A,C) and diffuse light (B,D). Symbols represent means, while dashed lines indicate \pm 1 S.D. $(n=3)$. The dotted line in $\mathrm{y}=0$ indicates the sediment surface, while the dotted line in $\mathrm{x}=0$ indicates a $0^{\circ} \mathrm{C}$ temperature change. irradiances of $>200 \mu \mathrm{mol}$ photons $\mathrm{m}^{-2} \mathrm{~s}^{-1}$ (Figure S3A). The thickness of the photic zone generally increased with increasing photon irradiance and varied from 0.4 to $1.2 \mathrm{~mm}$ in the biofilm under diffuse light and from 0.2 to $0.9 \mathrm{~mm}$ under collimated light.

In the coral sediment, the highest volume-specific rates of photosynthesis were measured within the upper $1 \mathrm{~mm}$, with maximal gross photosynthesis rates of $11.97 \mathrm{nmol} \mathrm{O}_{2} \mathrm{~cm}^{-3} \mathrm{~s}^{-1}$ at the sediment surface under collimated light and $3.05 \mathrm{nmol} \mathrm{O}_{2}$ $\mathrm{cm}^{-3} \mathrm{~s}^{-1}$ at a depth of $0.6 \mathrm{~mm}$ under diffuse light (Figure S3B). The photic zone in the coral sediment increased with increasing irradiance and ranged in thickness from 1.5 to $3 \mathrm{~mm}$ under diffuse light and from 2 to $3.5 \mathrm{~mm}$ under collimated light. The apparent stratification in $\mathrm{O}_{2}$ concentration found in the coral sediment was confirmed in the profiles of gross photosynthesis with peaks in gross photosynthesis in the upper $1 \mathrm{~mm}$ and 1.5-2.5 $\mathrm{mm}$ from the surface at photon irradiances $>50 \mu \mathrm{mol}$ photons $\mathrm{m}^{-2} \mathrm{~s}^{-1}$ (Figure S3B).

Under low photon irradiance $<200 \mu \mathrm{mol}$ photons $\mathrm{m}^{-2} \mathrm{~s}^{-1}$ in the biofilm, the area specific gross photosynthesis rate (PG) was higher under diffusive illumination, while PG under diffuse and collimated illumination were similar at higher irradiances (Figure 6). In contrast, PG in the coral sediment was generally in the range of 3-4 times lower under diffuse- compared to collimated light (Figure S3B; Figure 6B). We note that the gross photosynthesis measurements in the coral sediment under diffuse light were performed at the University of Technology Sydney (UTS) rather than on HIRS, where the rest of the measurements took place. We speculate that the transport from Heron Island created prolonged anoxic conditions throughout the sediment and this might have caused a change in community composition and structure of the sediment. These measurements were therefore excluded when calculating the light energy budget for diffuse light in the coral sediment.

\section{Energy Budgets}

The photosynthesis-irradiance (PE) curve of the coral sediment measured in diffuse light increased with increasing light intensity with an initial slope of $0.05 \pm 0.01$, until reaching an asymptotic saturation level at $\mathrm{JPS}_{\text {, max }}=1.72 \pm 0.20 \mathrm{~J} \mathrm{~m}^{-2} \mathrm{~s}^{-1}$ at a downwelling photon irradiance of $\sim 300 \mu \mathrm{mol}$ photons $\mathrm{m}^{-2} \mathrm{~s}^{-1}$ (Figure 6B). In contrast, the PE-curve of the coral sediment in collimated light increased with the with a slope of $0.26 \pm$ 0.04 , reaching a maximum saturation value of $\mathrm{JPS}$, max $=4.24$ $\pm 0.23 \mathrm{~J} \mathrm{~m}^{-2} \mathrm{~s}^{-1}$, at downwelling photon irradiance $\sim 110$ $\mu \mathrm{mol}$ photons $\mathrm{m}^{-2} \mathrm{~s}^{-1}$ (Figure 6B). In the biofilm, the onset of photosynthesis saturation occurred already at a downwelling photon irradiance of $\sim 50 \mu \mathrm{mol}$ photons $\mathrm{m}^{-2} \mathrm{~s}^{-1}$, where JPs,max reached an asymptotic saturation level of $0.87 \mathrm{~J} \mathrm{~m}^{-2} \mathrm{~s}^{-1}$ for both diffuse and collimated light (Figure 6A).

Sediment surface warming increased linearly with irradiance under both diffuse and collimated light with average slopes of $\mathrm{CS} \alpha_{\text {diff }}=4.33 \cdot 10^{-3}{ }^{\circ} \mathrm{C}\left(\mathrm{J} \mathrm{m}^{-2} \mathrm{~s}^{-1}\right)^{-1}$ and $\mathrm{CS} \alpha_{\text {coll }}=2.14 \cdot 10^{-3}$ ${ }^{\circ} \mathrm{C}\left(\mathrm{J} \mathrm{m}^{-2} \mathrm{~s}^{-1}\right)^{-1}$ in the coral sediment, as compared to $\mathrm{BF} \alpha_{\text {diff }}$ $=2.77 \cdot 10^{-3}{ }^{\circ} \mathrm{C}\left(\mathrm{J} \mathrm{m}^{-2} \mathrm{~s}^{-1}\right)^{-1}$ and $\mathrm{BF} \alpha_{\text {coll }}=2.0 \cdot 10^{-3}{ }^{\circ} \mathrm{C}(\mathrm{J}$ $\left.\mathrm{m}^{-2} \mathrm{~s}^{-1}\right)^{-1}$ in the biofilm (Figures 6C,D). Surface warming was stronger under diffuse light as compared to collimated light in both sediments (Figures 5, 6C,D). 


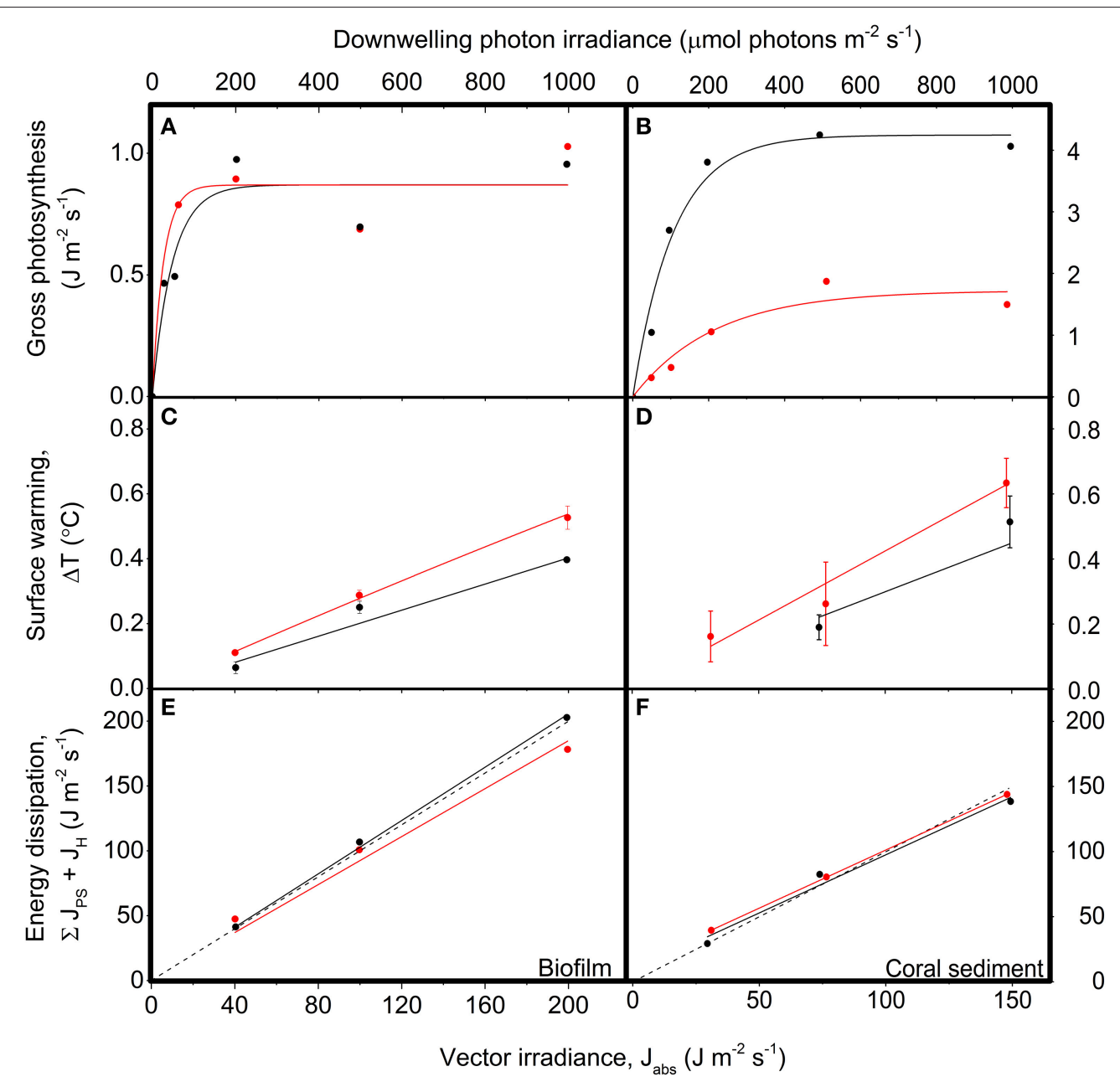

FIGURE 6 | Energy conversion by photosynthesis, heat dissipation and the sum of photosynthesis and heat dissipation vs. downwelling irradiance in biofilm (left panels) and corals sediment (right panels). Red symbols and lines show data for diffuse illumination, while black symbols and lines show data for collimated illumination. (A,B) Areal gross photosynthesis rates (in $\mathrm{J} \mathrm{m}^{-2} \mathrm{~s}^{-1}$ ) measured at downwelling photon irradiances of $0,50,100,200,500$, and 1,000 $\mu$ mol photons $\mathrm{m}^{-2} \mathrm{~s}^{-1}$, and then fitted with a saturated exponential model (Webb et al., 1974 ; CS: $R_{\text {diff }}^{2}=0.92, R_{\text {coll }}^{2}=0.97 ; \mathrm{BF}: R^{2}=0.88$ for both diffuse and collimated; $n=3$ ). (C,D) Temperature gradients (in ${ }^{\circ} \mathrm{C}$ ) between the ambient seawater and the sediment surface (flow $=0.5 \mathrm{~cm} \mathrm{~s}^{-1}$ ), measured at vector irradiances of 30,75 , and $149 \mathrm{~J} \mathrm{~m}^{-2} \mathrm{~s}^{-1}$ or 40,100 , and $200 \mathrm{~J} \mathrm{~m}^{-2} \mathrm{~s}^{-1}$ for the coral sediment and biofilm, respectively. Data points show means $\pm \mathrm{SD}(n=3)$; CS: $R_{\text {diff }}^{2}=$ $0.99, R_{\text {coll }}^{2}=0.96$; BF: $R^{2}=0.99$ for both diffuse and collimated light. (E,F) The summed energy dissipation of the system (in $\mathrm{J} \mathrm{m}^{-2} \mathrm{~s}^{-1}$ ), i.e., the sum of energy conserved by photosynthesis and energy dissipated as heat, measured at vector irradiances of 30,75, and $149 \mathrm{~J} \mathrm{~m}^{-2} \mathrm{~s}^{-1}$ and 40,100 , and $200 \mathrm{~J} \mathrm{~m} \mathrm{~m}^{-2} \mathrm{~s}^{-1}$ for the coral sediment and biofilm, respectively. The dashed line represents a 1:1 relationship between the incoming and outgoing energy of the system (i.e., the theoretically expected relationship). CS: $R_{\text {diff }}^{2}=0.99, R^{2}$ coll $=0.96$; BF: $R^{2}=0.99$ for both diffuse and collimated light; $(n=3)$.

The summed flux of energy conserved by photosynthesis and dissipated as heat $\left(\mathrm{J}_{\mathrm{PS}}+\mathrm{J}_{\mathrm{H}}\right.$ ) serves as a control to determine the potential deviations between absorbed and dissipated energy (Figures 6E,F). Dissipation of energy from the system increased linearly with increasing vector irradiance with slopes in the coral sediment of $0.89 \pm 0.003$ and $0.89 \pm 0.120$, for diffuse and collimated light respectively, and slopes in the biofilm of 0.93 and 1.03 , for diffuse and collimated light respectively. When all outgoing/used energy equals the incoming light energy the slope of the used- vs. incoming energy curve would be $=1$, and thus the method used here apparently accounted for the majority of the incident light energy.
About 29\% of the incident light energy was back-scattered from the coral sediment surface and thus not absorbed, whereas the surface reflection was only $\sim 2 \%$ of the incident irradiance in the biofilm (Figure 7; Figure S2). The fraction of energy conserved by photosynthesis decreased with increasing irradiance in both biofilm and sediment (Figures 7, 8). Over the investigated incident irradiances (200-1,000 $\mu \mathrm{mol}$ photons $\left.\mathrm{m}^{-2} \mathrm{~s}^{-1}\right)$, photosynthetic energy conservation in the coral sediment illuminated with diffuse light decreased from 6.7 to $2.0 \%$ of the incident light energy, favoring heat dissipation (which increased from 63.1 to $67.8 \%$ ), and from 9.3 to $2.1 \%$ of the incident light energy under collimated light (where 


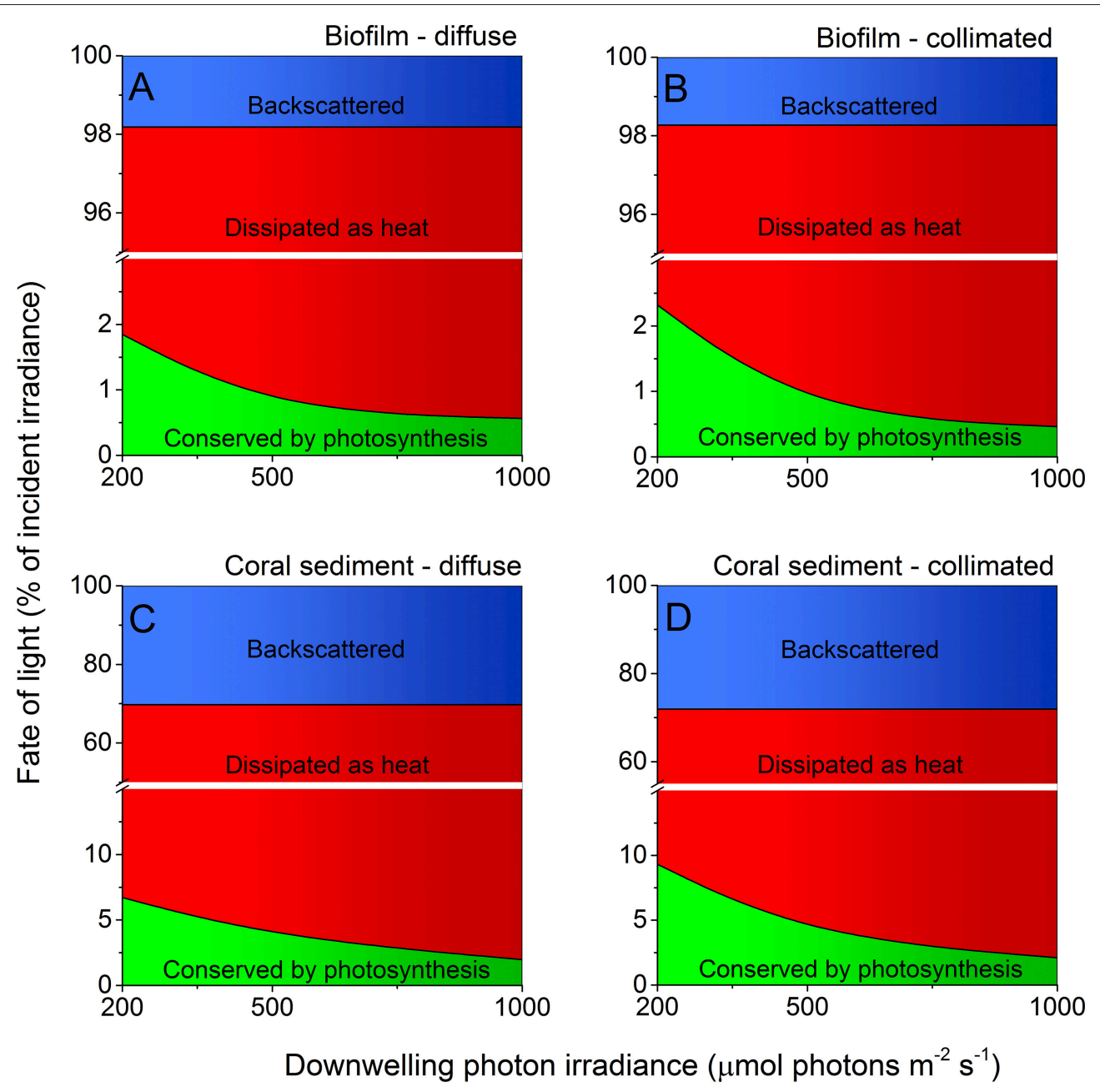

FIGURE 7 | Light energy budgets for biofilm (A,B) and coral sediment (C,D) in percent of the incident light energy calculated at downwelling photon irradiance (PAR) of 200, 500, and 1,000 $\mu \mathrm{mol}$ photons $\mathrm{m}^{-2} \mathrm{~s}^{-1}$, under diffuse (A,C) and collimated (B,D) incident light. The amount of light backscattered from the sediment surface is shown in blue, while the amount of light energy dissipated as heat and via photosynthesis is shown in red and green, respectively. Notice the break on the y-axis. We assumed similar GPP under diffuse and collimated light in the calculations for the coral sediment under diffuse light (see Table S1 and Figure S3).

heat dissipation increased from 62.6 to $69.8 \%$; Figure 7; Table S2).

Under an incident photon irradiance of $200 \mu \mathrm{mol}$ photons $\mathrm{m}^{-2} \mathrm{~s}^{-1}$, the proportion of incident light energy that was conserved via photosynthesis was much lower in the biofilm where 1.9 and $2.3 \%$ (diffuse and collimated light, respectively) of the incident light energy was conserved, whereas 96.3 and $96.0 \%$ of the incident light energy was dissipated as heat, respectively (Figure 7; Table S1). At an incident irradiance of $1,000 \mu \mathrm{mol}$ photons $\mathrm{m}^{-2} \mathrm{~s}^{-1}$, only 0.6 and $0.5 \%$ of the incident energy was conserved by photosynthesis, while 97.6 and $97.8 \%$ was dissipated as heat under diffuse and collimated light, respectively (Figure 7; Table S2).

The maximum photochemical energy conservation in the coral sediment was observed at an incident irradiance of $\sim 100$ $\mu \mathrm{mol}$ photons $\mathrm{m}^{-2} \mathrm{~s}^{-1}$ (18.1\% of the absorbed light energy), whereas the biofilm had maximum energy conservation through photosynthesis (14.7\% of the absorbed light energy) at the lowest measured incident irradiance $\left(50 \mu \mathrm{mol}\right.$ photons $\mathrm{m}^{-2} \mathrm{~s}^{-1}$; Figure 8). In addition, the biofilm had higher photosynthetic efficiencies under diffuse light compared to collimated light at low light intensities ( $<200 \mu \mathrm{mol}$ photons $\mathrm{m}^{-2} \mathrm{~s}^{-1}$; Figure 8$)$.

The photosynthetic efficiencies of biofilm and coral sediment under light-limiting conditions $\left(\mathrm{J}_{\mathrm{ABS}} \rightarrow 0\right), \quad \varepsilon \mathrm{PS}$,max, were calculated from the initial slope of the areal PG vs. vector irradiance curve to $26.2 \%$ of the absorbed light energy (CS, collimated light) compared to 16 and $9.0 \%$ of the absorbed light energy (BF, diffuse and collimated light, respectively).

\section{DISCUSSION}

We present a closed radiative energy budget of a heterogeneous coral reef sediment and compare it to the radiative energy budget of a flat dense biofilm (Figure 6; Figure S4). The closed light energy budgets were measured under both diffuse and collimated illumination to test potential effects of the directionality of light 


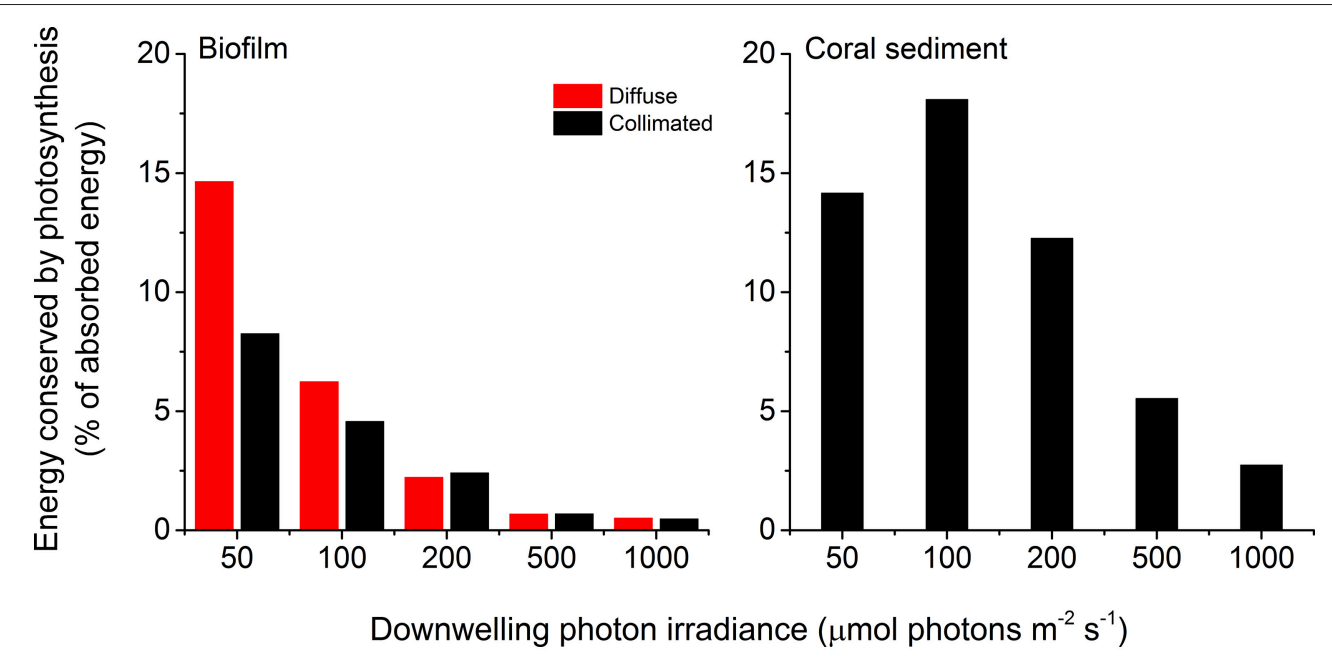

FIGURE 8 | Photosynthetic energy conservation efficiencies (in \% of the absorbed light energy) of the biofilm (left panel) and the coral sediment (right panel), measured at incident photon irradiances of 50, 100, 200,500, and 1,000 $\mu$ mol photons $\mathrm{m}^{-2} \mathrm{~s}^{-1}$, under diffuse (red bars), and collimated (black bars) light.

on the photosynthetic efficiencies of the phototrophs. We found that a higher fraction of the absorbed light energy was conserved by photosynthesis in the heterogenous loosely organized coral sediment, while the radiative energy budgets of both sediment types were highly dominated by dissipation of heat.

\section{Light}

The thin highly pigmented cyanobacterial biofilm was growing on the surface of a fine-grained (125-250 $\mu \mathrm{m})$ dark sandy sediment, whereas the photosynthetic microorganisms exhibited a more patchy distribution within the large-grained (100-500 $\mu \mathrm{m})$ bright and highly scattering coral sediment. This structural difference between the two systems led to a $\sim 15$ times higher surface reflection and a decreased energy absorption in the coral sediment compared to the biofilm that displayed $>8$ times higher light attenuation coefficients. As previously shown (Lassen et al., 1992b; Kühl and Fenchel, 2000) the scalar irradiance at, or immediately below, the surface increased, and the spectral composition was altered relative to the incident irradiance (Figures 2, 3). Such increase in scalar irradiance in the near surface layer is due to intense multiple scattering by particles (biotic and abiotic) causing a local photon path-length increase and thus a prolonged residence time of scattered photons in the surface layers that also receive a continuous supply of incident photons from the light source (Kühl and Jørgensen, 1994). This effect can be further enhanced in the presence of exopolymers with a slightly higher refractive index than the surrounding seawater leading to photon trapping effects (Kühl and Jørgensen, 1994; Decho et al., 2003). Furthermore, the structural difference between the loosely organized $\mathrm{CaCO}_{3}$ particles compared to the flat biofilm could possibly result in differences in the reflection characteristics from the uppermost layers. In the biofilm, the flat homogeneous surface reflects light relatively uniformly, with some ratio between specular vs. diffuse reflection. However, in the heterogeneous coral sediment a higher degree of forward scattering will most likely be present as the angle of reflection will be more complex due to the roughness of the surface, resulting in a deeper penetration of light in the coral sediment.

\section{Temperature}

We directly measured both the upward and downward heat dissipation of radiative energy (Figure 5). Previous studies of energy budgets ignored the downward heat flux (Al-Najjar et al., 2010, 2012), and although Jimenez et al. (2008) estimated the downward heat dissipation from a theoretical model considering the physical properties of heat transfer in coral skeleton, this study presents energy budgets of phototrophic systems for which the complete heat balance was directly measured. Over a range of incident irradiances, the downward heat flux was the same order of magnitude as the upward heat flux in both biofilm and coral sediment and thus is an important parameter when compiling light energy budgets for the photic zone in benthic systems (Figure 5).

The majority of the absorbed light energy was dissipated as heat (Figure 7; Table S1) with a linear relationship between increasing incident irradiance and heat dissipation under both diffuse and collimated light, albeit with a $~ 30 \%$ enhanced surface warming under diffuse light as compared to collimated light (Figures 5, 6). Apparently, diffuse light was absorbed more efficiently in the uppermost layers, increasing the local photon density and residence time in these layers resulting in increased energy deposition and surface temperatures. This was supported by a higher heat flux into the water column under diffuse light, and a higher heat flux into the sediment under collimated light (data not shown). At increasing irradiances the surface temperature of the sediments exceeded the surrounding water temperature and convective heat transport occurred over the TBL (Figure 5; Jimenez et al., 2011). While we cannot dissect the observed heat dissipation into particular mechanisms and their relative magnitude, part of such dissipation in optically dense 
biofilms and sediments involves NPQ processes that protect the photosynthetic apparatus under high irradiance by channeling excess light energy into heat dissipation (Falkowski and Raven, 2007; Al-Najjar et al., 2012). The heat fluxes from the photic zone were generally higher in the biofilm when compared to the coral sediment, due to the lower reflection and thus higher absorption in the biofilm (Figure S4). However, when normalizing the heat fluxes to the absorbed light energy (which was 33\% higher in the biofilm than in the coral sediment) the heat dissipation was of similar magnitude, and variations in heat flux values between the sediment and biofilm became $<15 \%$. The degree of heat dissipation therefore seems tightly correlated to the quantity of absorbed energy.

\section{Photosynthesis}

The overall photosynthetic efficiency of the biofilm and coral sediment decreased with increasing incident irradiance, with photosynthesis exhibiting saturation at higher irradiance under both diffuse and collimated light (Figure 6). The highest energy storage efficiency of the coral sediment was observed under lightlimiting conditions $\left(<200 \mu \mathrm{mol}\right.$ photons $\mathrm{m}^{-2} \mathrm{~s}^{-1}$; Figures 7 , 8), and the coral sediment generally exhibited high light use efficiencies that were comparable to those observed in corals at equivalent incident photon irradiances (Brodersen et al., 2014). The photosynthetic activity in the coral sediment was stratified at incident irradiances $>50 \mu \mathrm{mol}$ photons $\mathrm{m}^{-2} \mathrm{~s}^{-1}$ under both diffuse and collimated light (Figure 4). This stratification could be a result of different factors influencing the photosynthetic activity such as steep light attenuation over depth, locally high volume-specific rates of metabolic activity, higher local biomass of phototrophs, and diffusion limitation of metabolic products and substrates (Kühl et al., 1996; Kühl and Fenchel, 2000; Al-Najjar et al., 2012). Such vertical stratification has also been associated with phototactic responses to light (Whale and Walsby, 1984; Lassen et al., 1992b), where motile photosynthetic organisms migrate to an optimal depth for photosynthesis at a given irradiance, where the available light is neither limiting nor inhibiting the rate of photosynthesis (Al-Najjar et al., 2012). These migration patterns are well documented both as photoand aero-tactic responses and to escape from e.g., toxic levels of sulfide (Kühl et al., 1994; Bebout and Garcia-Pichel, 1995). The two photosynthetic active layers were situated at the sediment surface and $\sim 2 \mathrm{~mm}$ below ( $\sim 0.5$ and $1 \mathrm{~mm}$ thick layers, respectively; Figure 3).

The area-specific rates of gross photosynthesis of the coral sediment were $\sim 4$ times higher than in the biofilm, due to a $\sim 3$ times deeper euphotic zone and slightly higher volumespecific photosynthesis rates in the coral sediment than in the biofilm (Figures 6, 7; Figure S3). Consequently, the coral sediment reached an asymptotic maximum in PG in terms of energy dissipation via photosynthesis of $\sim 4.2 \mathrm{~J} \mathrm{~m}^{-2} \mathrm{~s}^{-1}$ as compared to only $\sim 0.9 \mathrm{~J} \mathrm{~m}^{-2} \mathrm{~s}^{-1}$ in the biofilm (Figure 6). The $\mathrm{E}_{\mathrm{k}}$ value, i.e., the irradiance at the onset of photosynthesis saturation, was $>2$ higher in the coral sediment compared to the Danish biofilm, which reflects the different in situ light conditions experienced by the two systems in their respective geographic locations (Denmark: $55^{\circ} \mathrm{N}$, Heron Island: $23^{\circ} \mathrm{S}$ ). Thus, the dense biofilm appeared acclimated to low irradiances as previously shown (Kühl et al., 1996; Kühl and Fenchel, 2000; Al-Najjar et al., 2012) where highly reduced quantum efficiencies are seen at increasing irradiance due to the employment of e.g., NPQ processes. Accordingly, the coral sediment maintained higher photosynthetic efficiencies, even at high irradiance. This could in part be explained by the high scattering in the sediment particles that creates a more even spread of the light field over the sediment matrix and a more dispersed photic zone; a factor that have been speculated to be responsible for the high photosynthesis in coral tissues (Brodersen et al., 2014; Wangpraseurt et al., 2014a). A more homogenous distribution of light would create a larger region where light is neither limiting nor inhibiting photosynthesis. Thus, the loosely organized more heterogenous coral sediment apparently exhibit a more open, canopy-like organization compared to the dense biofilm.

Community photosynthesis is generally higher than that of individual phytoelements (Binzer and Sand-Jensen, 2002; Binzer and Middelboe, 2005; Binzer et al., 2006) and in addition, higher community photosynthesis has been found under diffuse illumination in open canopy systems which was explained by a more even light field inside the canopy (Gu et al., 2002; Brodersen et al., 2008). In spite of this difference in overall acclimation to light, a decrease in the surface layer photosynthesis was seen in the coral sediment at an incident irradiance of $500 \mu \mathrm{mol}$ photons $\mathrm{m}^{-2} \mathrm{~s}^{-1}$, which could either reflect the heterogeneity and patchiness of the phototrophs found in the sediment, or could point to a possible migration of motile phototrophic organisms. Migration as a phototactic response is recognized as an effective mechanism for controlling photon absorption across different systems such as terrestrial plants (Wada et al., 2003) and microphytobenthic assemblages (Serodio et al., 2006; Cartaxana et al., 2016a,b), and similar phototactic response has been shown in coral tissues where the in hospite light environment can be modulated by host tissue movement (Wangpraseurt et al., 2014a, 2017). Downward migration at high irradiances is probably correlated with increasing photic stress e.g., by the formation of reactive oxygen species that can damage photosystem II by preventing the synthesis of the D1 protein in these layers (Hihara et al., 2001; Nishiyama et al., 2001; Aarti et al., 2007; Latifi et al., 2009; Al-Najjar et al., 2010). Several ways to counter such photic stress exists. One of the most effective short-term responses to photic stress is to employ NPQ in which photons are emitted as heat when cells experience over-saturating photon fluxes. Another strategy to avoid photo-damage is to upregulate the expression of sun-protective pigments such as $\beta$-carotenes (Zhu et al., 2010), which were found in significant amounts by HPLC analysis of the coral sediment (Figure S1).

Photosynthetic energy conservation was higher under collimated light as compared to illumination with diffuse light at moderate irradiance $\left(200 \mu \mathrm{mol}\right.$ photons $\mathrm{m}^{-2} \mathrm{~s}^{-1}$; Figure 6). This finding correlates with previous studies of individual terrestrial leaves reporting $10-15 \%$ higher energy conservation via photosynthesis under collimated- relative to diffuse light (Brodersen et al., 2008) and in corals it has been shown that gross photosynthesis was 2-fold higher under direct vs. diffuse light (Wangpraseurt and Kühl, 2014). In terrestrial leaves, the 
more efficient utilization of collimated light has been ascribed to specialized tissue structures such as columnar palisade cells (Vogelmann and Martin, 1993), that increase the absorptance of direct light over diffuse light (Brodersen and Vogelmann, 2007). Furthermore, light-induced chloroplast movement has been shown to be less effective under diffuse illumination (Gorton et al., 1999; Williams et al., 2003). In corals the higher photosynthesis at the tissue surface was explained by optical properties enhancing the scalar irradiance near the surface under direct illumination (Wangpraseurt and Kühl, 2014). This tendency changed dramatically in the dense photosynthetic biofilm at light-limiting conditions $\left(\leq 100 \mu \mathrm{mol}\right.$ photons $\mathrm{m}^{-2}$ $\mathrm{s}^{-1}$ ) favoring effective light utilization under diffuse light (Figure 7). Thus, the optical properties and the structural organization of phytoelements seem tightly linked to the photosynthetic quantum efficiencies across different systems and light angularity may therefore elicit differential photosynthetic responses depending on the system and on the scale at which it is studied.

\section{CONCLUSION}

Our results show that a higher fraction of the absorbed light energy was conserved by photosynthesis in the heterogeneous coral sediment due to a deeper photic zone and slower saturation of photosynthesis with increasing irradiance in the more open structure of the sediment microcanopy as compared to the flat and highly absorbing biofilm. The balanced radiative energy budget of biofilm and coral sediment was highly dominated by heat dissipation and the efficiency of photosynthetic energy conservation decreased with increasing irradiance. Although the two systems exhibited similar heat dissipation, the photic zones wherein such dissipation took place was very different e.g., by a three times deeper photic zone in the coral sediment than in the biofilm. In addition, several variances were found between illumination with diffuse or collimated light: (i) diffuse light enhanced dissipation of heat $(\sim 30 \%)$ in the upper sediment layers as compared to collimated light; (ii) at low incident irradiance $(200 \mu \mathrm{mol}$ photons $\mathrm{m}^{-2} \mathrm{~s}^{-1}$ ) photosynthetic energy conservation was higher (3-4\% of the absorbed light energy) in collimated light as

\section{REFERENCES}

Aarti, D., Tanaka, R., Ito, H., and Tanaka, A. (2007). High light inhibits chlorophyll biosynthesis at the level of 5-aminolevulinate synthesis during de-etiolation in cucumber (Cucumis sativus) cotyledons. Photochem. Photobiol. 83, 171-176. doi: 10.1562/2006-03-06-RA-835

Al-Najjar, M. A. A., de Beer, D., Jørgensen, B. B., Kühl, M., and Polerecky, L. (2010). Conversion and conservation of light energy in a photosynthetic microbial mat ecosystem. ISME J. 4, 440-449. doi: 10.1038/ismej. 2009.121

Al-Najjar, M. A., de Beer, D., Kühl, M., and Polerecky, L. (2012). Light utilization efficiency in photosynthetic microbial mats. Environ. Microbiol. 14, 982-992. doi: 10.1111/j.1462-2920.2011.02676.x

Bebout, B. M., and Garcia-Pichel, F. (1995). Uv B-induced vertical migrations of cyanobacteria in a microbial mat. Appl. Environ. Microbiol. 61, 4215-4222. compared to diffuse light; a tendency that dramatically changed in the photosynthetic biofilm at low and light-limiting incident irradiances ( $\leq 100 \mu \mathrm{mol}$ photons $\mathrm{m}^{-2} \mathrm{~s}^{-1}$ ) favoring effective light utilization under diffuse light (up to a $\sim 2$-fold increase). However, cyanobacterial and diatom dominated mats have been shown to migrate vertically employing photo- and/or chemotactic responses (Richardson and Castenholz, 1987; Bhaya, 2004; Serodio et al., 2006; Coelho et al., 2011; Cartaxana et al., 2016a) and the motility of the phototrophs was not considered here. Thus, there is a need to further explore how vertical migration affects the radiative energy balance and thereby the light use efficiency in microbenthic systems such as sediments and biofilms.

\section{AUTHOR CONTRIBUTIONS}

$\mathrm{ML}, \mathrm{KB}$, and $\mathrm{MK}$ designed the experiments; $\mathrm{ML}$ and $\mathrm{KB}$ performed experiments; $\mathrm{ML}, \mathrm{KB}$, and $\mathrm{MK}$ analyzed data; $\mathrm{ML}$ wrote the paper with editorial inputs from $\mathrm{KB}$ and $\mathrm{MK}$.

\section{ACKNOWLEDGMENTS}

We thank P. J. Ralph, P. Brooks, M. Zbinden and other colleagues at University of Technology Sydney (C3, UTS) for access to laboratory facilities, technical support and help with HPLC analysis of the coral sediment. We thank the staff at Heron Island Research Station for technical assistance during the field work. V. Schrameyer, D. Wangpraseurt and D. A. Nielsen are thanked for thoughtful discussions. The research was conducted under research permits for field work on the Great Barrier Reef, Australia (G11/34670.1 and G09/31733.1) and was funded by the Danish Council for Independent Research|Natural Sciences (MK), the Knud Højgaards Fund, the Oticon Foundation, Thorsons Travel Grant and Københavns Universitets Fœlleslegat (ML, KB).

\section{SUPPLEMENTARY MATERIAL}

The Supplementary Material for this article can be found online at: http://journal.frontiersin.org/article/10.3389/fmicb. 2017.00452/full\#supplementary-material

Bhaya, D. (2004). Light matters: phototaxis and signal transduction in unicellular cyanobacteria. Mol. Microbiol. 53, 745-754. doi: 10.1111/j.1365-2958.2004. 04160.x

Binzer, T., and Middelboe, A. L. (2005). From thallus to communities: scale effects and photosynthetic performance in macroalgae communities. Mar. Ecol. Prog. Ser. 287, 65-75. doi: 10.3354/meps 287065

Binzer, T., and Sand-Jensen, K. (2002). Production in aquatic macrophyte communities: a theoretical and empirical study of the influence of spatial light distribution. Limnol. Oceanogr. 47, 1742-1750. doi: 10.4319/lo.2002.47. 6.1742

Binzer, T., Sand-Jensen, K., and Middelboe, A. L. (2006). Community photosynthesis of aquatic macrophytes. Limnol. Oceanogr. 51, 2722-2733. doi: 10.4319/lo.2006.51.6.2722

Bird, R. E., and Riordan, C. (1986). Simple solar spectral model for direct and diffuse irradiance on horizontal and tilted planes at the earths 
surface for cloudless atmospheres. J. Clim. Appl. Meteorol. 25, 87-97. doi: 10.1175/1520-0450(1986)025<0087:SSSMFD >2.0.CO;2

Brakel, W. H. (1979). Small-scale spatial variation in light available to Coral-Reef Benthos - quantum Irradiance measurements from a Jamaican Reef. Bull. Mar. Sci. $29,406-413$.

Brodersen, C. R., and Vogelmann, T. C. (2007). Do epidermal lens cells facilitate the absorptance of diffuse light? Am. J. Bot. 94, 1061-1066. doi: 10.3732/ajb.94.7.1061

Brodersen, C. R., Vogelmann, T. C., Williams, W. E., and Gorton, H. L. (2008). A new paradigm in leaf-level photosynthesis: direct and diffuse lights are not equal. Plant Cell Environ. 31, 159-164. doi: 10.1111/j.1365-3040.2007.01751.x

Brodersen, K. E., Lichtenberg, M., Ralph, P. J., Kühl, M., and Wangpraseurt, D. (2014). Radiative energy budget reveals high photosynthetic efficiency in symbiont-bearing corals. J. R. Soc. Interface 11:20130997. doi: 10.1098/rsif.2013.0997

Cartaxana, P., Cruz, S., Gameiro, C., and Kühl, M. (2016a). Regulation of intertidal microphytobenthos photosynthesis over a diel emersion period is strongly affected by diatom migration patterns. Front. Microbiol. 7:872. doi: $10.3389 /$ fmicb.2016.00872

Cartaxana, P., Ribeiro, L., Goessling, J. W. L., Cruz, S., and Kühl, M. (2016b). Light and $\mathrm{O} 2$ microenvironments in two contrasting diatom-dominated coastal sediments. Mar. Ecol. Prog. Ser. 545, 35-47. doi: 10.3354/meps11630

Clauser, C., and Huenges, E. (1995). "Thermal conductivity of rocks and minerals," in Rock Physics \& Phase Relations: A Handbook of Physical Constants, ed T. J. Ahrens (Washington, DC: American Geophysical Union), 105-126.

Coelho, H., Vieira, S., and Serodio, J. (2011). Endogenous versus environmental control of vertical migration by intertidal benthic microalgae. Eur. J. Phycol. 46, 271-281. doi: 10.1080/09670262.2011.598242

Colyer, C. L., Kinkade, C. S., Viskari, P. J., and Landers, J. P. (2005). Analysis of cyanobacterial pigments and proteins by electrophoretic and chromatographic methods. Anal. Bioanal. Chem. 382, 559-569. doi: 10.1007/s00216-004-3020-4

Decho, A. W., Kawaguchi, T., Allison, M., Louchard, E., Reid, P., Stephens, F. C., et al. (2003). Sediment properties influencing upwelling spectral reflectance signatures: the "biofilm gel effect." Limnol. Oceanogr. 48, 431-443. doi: 10.4319/lo.2003.48.1_part_2.0431

Falkowski, P., and Raven, J. A. (2007). Aquatic Photosynthesis, 2nd Edn. Princeton, NJ: Princeton University Press.

Gorton, H. L., Brodersen, C. R., Williams, W. E., and Vogelmann, T. C. (2010). Measurement of the optical properties of leaves under diffuse light. Photochem. Photobiol. 86, 1076-1083. doi: 10.1111/j.1751-1097.2010.00761.x

Gorton, H. L., Williams, W. E., and Vogelmann, T. C. (1999). Chloroplast movement in Alocasia macrorrhiza. Physiol. Plant. 106, 421-428. doi: 10.1034/j.1399-3054.1999.106410.x

Gu, L. H., Baldocchi, D., Verma, S. B., Black, T. A., Vesala, T., Falge, E. M., et al. (2002). Advantages of diffuse radiation for terrestrial ecosystem productivity. J. Geophys. Res. Atmos. 107, ACL 2-1-ACL 2-23. doi: 10.1029/2001JD001242

Gu, L. H., Fuentes, J. D., Shugart, H. H., Staebler, R. M., and Black, T. A. (1999). Responses of net ecosystem exchanges of carbon dioxide to changes in cloudiness: results from two North American deciduous forests. J. Geophys. Res. Atmos. 104, 31421-31434. doi: 10.1029/1999JD901068

Henriksen, P., Andersen, J., Carstensen, J., Christiansen, T., Conley, D., Dahl, K., et al. (2001). "Marine areas 2000-Environmental condition and development," in NOVA 2003 (Danmarks Miljøundersøgelser (DMU)). Available online at: http://www.dmu.dk/1_viden/2_Publikationer/3_fagrapporter/rapporter/ FR375.pdf

Hihara, Y., Kamei, A., Kanehisa, M., Kaplan, A., and Ikeuchi, M. (2001). DNA microarray analysis of cyanobacterial gene expression during acclimation to high light. Plant Cell 13, 793-806. doi: 10.1105/tpc.13.4.793

Jimenez, I. M., Kühl, M., Larkum, A. W. D., and Ralph, P. J. (2008). Heat budget and thermal microenvironment of shallow-water corals: do massive corals get warmer than branching corals? Limnol. Oceanogr. 53, 1548-1561. doi: $10.4319 /$ lo.2008.53.4.1548

Jimenez, I. M., Kühl, M., Larkum, A. W. D., and Ralph, P. J. (2011). Effects of flow and colony morphology on the thermal boundary layer of corals. J. R. Soc. Interface 8, 1785-1795. doi: 10.1098/rsif.2011.0144

Jimenez, I. M., Larkum, A. W. D., Ralph, P. J., and Kühl, M. (2012). In situ thermal dynamics of shallow water corals is affected by tidal patterns and irradiance. Mar. Biol. 159, 1773-1782. doi: 10.1007/s00227-012-1968-8
Jørgensen, B. B., and Des Marais, D. J. (1988). Optical properties of benthic photosynthetic communities - fiber-optic studies of cyanobacterial mats. Limnol. Oceanogr. 33, 99-113. doi: 10.4319/lo.1988.33.1.0099

Jørgensen, B. B., and Des Marais, D. J. (1990). The diffusive boundary layer of sediments - oxygen microgradients over a microbial mat. Limnol. Oceanogr. 35, 1343-1355. doi: 10.4319/lo.1990.35.6.1343

Kirk, J. (1994). Light and Photosynthesis in Aquatic Ecosystems. New York, NY: Cambridge University Press.

Krakauer, N. Y., and Randerson, J. T. (2003). Do volcanic eruptions enhance or diminish net primary production? Evidence from tree rings. Global Biogeochem. Cycles 17, 1118. doi: 10.1029/2003GB002076

Kühl, M. (2005). Optical microsensors for analysis of microbial communities. Environ. Microbiol. 397, 166-199. doi: 10.1016/s0076-6879(05) 97010-9

Kühl, M., and Fenchel, T. (2000). Bio-optical characteristics and the vertical distribution of photosynthetic pigments and photosynthesis in an artificial cyanobacterial mat. Microb. Ecol. 40, 94-103. doi: 10.1007/s002480000061

Kühl, M., Glud, R. N., Ploug, H., and Ramsing, N. B. (1996). Microenvironmental control of photosynthesis and photosynthesis-coupled respiration in an epilithic cyanobacterial biofilm. J. Phycol. 32, 799-812. doi: $10.1111 / \mathrm{j} .0022-3646.1996 .00799 . \mathrm{x}$

Kühl, M., and Jørgensen, B. B. (1994). The light-field of microbenthic communities - radiance distribution and microscale optics of sandy coastal sediments. Limnol. Oceanogr. 39, 1368-1398. doi: 10.4319/lo.1994.39.6.1368

Kühl, M., Lassen, C., and Jørgensen, B. (1994). "Optical properties of microbial mats: light measurements with fiber-optic microprobes," in Microbial Mats, eds L. Stal and P. Caumette (Berlin; Heidelberg: Springer), 149-166.

Kühl, M., Lassen, C., and Revsbech, N. P. (1997). A simple light meter for measurements of PAR (400 to $700 \mathrm{~nm}$ ) with fiber-optic microprobes: application for P vs E-0(PAR) measurements in a microbial mat. Aquatic Microb. Ecol. 13, 197-207. doi: 10.3354/ame013197

Lassen, C., Ploug, H., and Jørgensen, B. B. (1992a). A fiberoptic scalar irradiance microsensor - application for spectral light measurements in sediments. FEMS Microbiol. Ecol. 86, 247-254. doi: 10.1111/j.1574-6968.1992.tb04816.x

Lassen, C., Ploug, H., and Jørgensen, B. B. (1992b). Microalgal photosynthesis and spectral scalar irradiance in coastal marine sediments of Limfjorden, Denmark. Limnol. Oceanogr. 37, 760-772. doi: 10.4319/lo.1992.37.4.0760

Latifi, A., Ruiz, M., and Zhang, C. C. (2009). Oxidative stress in cyanobacteria. FEMS Microbiol. Rev. 33, 258-278. doi: 10.1111/j.1574-6976.2008.00134.x

Lichtenberg, M., Larkum, A. W., and Kühl, M. (2016). Photosynthetic acclimation of Symbiodinium in hospite depends on vertical position in the tissue of the scleractinian coral Montastrea curta. Front. Microbiol. 7:230. doi: $10.3389 /$ fmicb.2016.00230

Lichtenberg, M., Nørregaard, R. D., and Kühl, M. (2017). Diffusion or advection? Mass transfer and complex boundary layer landscapes of the brown alga Fucus vesiculosus. J. R. Soc. Interface 14:20161015. doi: 10.1098/rsif.2016.1015

Lovell, M. A. (1985). Thermal conductivities of marine sediments. Q. J. Eng. Geol. 18, 437-441. doi: 10.1144/GSL.QJEG.1985.018.04.14

Misson, L., Lunden, M., McKay, M., and Goldstein, A. H. (2005). Atmospheric aerosol light scattering and surface wetness influence the diurnal pattern of net ecosystem exchange in a semi-arid ponderosa pine plantation. Agric. Forest Meteorol. 129, 69-83. doi: 10.1016/j.agrformet.2004.11.008

Müller, P., Li, X. P., and Niyogi, K. K. (2001). Non-photochemical quenching. A response to excess light energy. Plant Physiol. 125, 1558-1566. doi: 10.1104/pp.125.4.1558

Murata, N., Takahashi, S., Nishiyama, Y., and Allakhverdiev, S. I. (2007), Photoinhibition of photosystem II under environmental stress. Biochim. Biophys. Acta-Bioenergetics 1767, 414-421. doi: 10.1016/j.bbabio.2006.11.019

Nielsen, M., Revsbech, N. P., and Kühl, M. (2015). Microsensor measurements of hydrogen gas dynamics in cyanobacterial microbial mats. Front. Microbiol. 6:726. doi: $10.3389 /$ fmicb.2015.00726

Nishiyama, Y., Yamamoto, H., Allakhverdiev, S. I., Inaba, M., Yokota, A., and Murata, N. (2001). Oxidative stress inhibits the repair of photodamage to the photosynthetic machinery. EMBO J. 20, 5587-5594. doi: 10.1093/emboj/20.20.5587

Nymark, M., Valle, K. C., Brembu, T., Hancke, K., Winge, P., Andresen, K., et al. (2009). An integrated analysis of molecular acclimation to high 
light in the marine diatom Phaeodactylum tricornutum. PLoS ONE 4:e7743. doi: 10.1371/journal.pone.0007743

Revsbech, N. P. (1989). An oxygen microsensor with a guard cathode. Limnol. Oceanogr. 34, 474-478. doi: 10.4319/lo.1989.34.2.0474

Revsbech, N. P., and Jørgensen, B. B. (1983). Photosynthesis of benthic microflora measured with high spatial-resolution by the oxygen microprofile method capabilities and limitations of the method. Limnol. Oceanogr. 28, 749-756. doi: 10.4319/lo.1983.28.4.0749

Richardson, L. L., and Castenholz, R. W. (1987). Diel vertical movements of the Cyanobacterium Oscillatoria-Terebriformis in a Sulfide-Rich hot-spring microbial mat. Appl. Environ. Microbiol. 53, 2142-2150.

Schiermeier, Q. (2006). Oceans cool off in hottest years. Nature 442, 854-855. doi: $10.1038 / 442854 \mathrm{a}$

Serodio, J., Coelho, H., Vieira, S., and Cruz, S. (2006). Microphytobenthos vertical migratory photoresponse as characterised by light-response curves of surface biomass. Estuarine Coast. Shelf Sci. 68, 547-556. doi: 10.1016/j.ecss.2006.03.005

Shashar, N., Kinane, S., Jokiel, P. L., and Patterson, M. R. (1996). Hydromechanical boundary layers over a coral reef. J. Exp. Mar. Biol. Ecol. 199, 17-28. doi: 10.1016/0022-0981(95)00156-5

Smith, G. B., Jonsson, J. C., and Franklin, J. (2003). Spectral and global diffuse properties of high-performance translucent polymer sheets for energy efficient lighting and skylights. Appl. Opt. 42, 3981-3991. doi: 10.1364/AO.42.003981

Smith, J. S., and Johnson, C. R. (1995). Nutrient inputs from seabirds and humans on a populated coral cay. Mar. Ecol. Prog. Ser. 124, 189-200. doi: $10.3354 /$ meps 124189

Thauer, R. K., Jungermann, K., and Decker, K. (1977). Energy conservation in chemotrophic anaerobic bacteria. Bacteriol. Rev. 41, 100-180.

Urban, O., Janous, D., Acosta, M., Czerny, R., Markova, I., Navratil, M., et al. (2007). Ecophysiological controls over the net ecosystem exchange of mountain spruce stand. Comparison of the response in direct vs. diffuse solar radiation. Global Change Biol. 13, 157-168. doi: 10.1111/j.1365-2486.2006.01265.x

Vogelmann, T. C., and Martin, G. (1993). The functional-significance of palisade tissue - penetration of directional versus diffuse light. Plant Cell Environ. 16, 65-72. doi: 10.1111/j.1365-3040.1993.tb00845.x

Wada, M., Kagawa, T., and Sato, Y. (2003). Chloroplast movement. Annu. Rev. Plant Biol. 54, 455-468. doi: 10.1146/annurev.arplant.54.031902.135023

Wangpraseurt, D., and Kühl, M. (2014). "Direct and diffuse light propagation through coral tissue," in Proceedings of SPIE. Optical Interactions with Tissue and Cells XXV; and Terahertz for Biomedical Applications, eds E. D. Jansen,
R. J. Thomas, G. J. Wilmink, and B. L. Ibey (San Francisco, CA: SPIE), 894117-1-894117-6.

Wangpraseurt, D., Larkum, A. W., Franklin, J., Szabó, M., Ralph, P. J., and Kühl, M. (2014a). Lateral light transfer ensures efficient resource distribution in symbiont-bearing corals. J. Exp. Biol. 217, 489-498. doi: 10.1242/jeb.091116

Wangpraseurt, D., Polerecky, L., Larkum, A. W. D., Ralph, P. J., Nielsen, D. A., Pernice, M., et al. (2014b). The in situ light microenvironment of corals. Limnol. Oceanogr. 59, 917-926. doi: 10.4319/lo.2014.59.3.0917

Wangpraseurt, D., Wentzel, C., Jacques, S. L., Wagner, M., and Kühl, M. (2017). In vivo imaging of coral tissue and skeleton with optical coherence tomography. J. R. Soc. Interface 14:20161003. doi: 10.1101/088682

Webb, W. L., Newton, M., and Starr, D. (1974). Carbon-dioxide exchange of Alnusrubra - mathematical-model. Oecologia 17, 281-291. doi: 10.1007/BF00345747

Werner, U., Bird, P., Wild, C., Ferdelman, T., Polerecky, L., Eickert, G., et al. (2006). Spatial patterns of aerobic and anaerobic mineralization rates and oxygen penetration dynamics in coral reef sediments. Mar. Ecol. Prog. Ser. 309, 93-105. doi: 10.3354/meps309093

Whale, G. F., and Walsby, A. E. (1984). Motility of the cyanobacterium Microcoleus chthonoplastes in mud. Br. Phycol. J. 19, 117-123. doi: 10.1080/00071618400650121

Williams, W. E., Gorton, H. L., and Witiak, S. M. (2003). Chloroplast movements in the field. Plant Cell Environ. 26, 2005-2014. doi: 10.1046/j.0016-8025.2003.01117.x

Zhu, Y. H., Graham, J. E., Ludwig, M., Xiong, W., Alvey, R. M., Shen, G. Z., et al. (2010). Roles of xanthophyll carotenoids in protection against photoinhibition and oxidative stress in the cyanobacterium Synechococcus sp strain PCC 7002. Arch. Biochem. Biophys. 504, 86-99. doi: 10.1016/j.abb.2010. 07.007

Conflict of Interest Statement: The authors declare that the research was conducted in the absence of any commercial or financial relationships that could be construed as a potential conflict of interest.

Copyright (C) 2017 Lichtenberg, Brodersen and Kühl. This is an open-access article distributed under the terms of the Creative Commons Attribution License (CC BY). The use, distribution or reproduction in other forums is permitted, provided the original author(s) or licensor are credited and that the original publication in this journal is cited, in accordance with accepted academic practice. No use, distribution or reproduction is permitted which does not comply with these terms. 


\section{APPENDIX}

Definition of abbreviations and parameters.

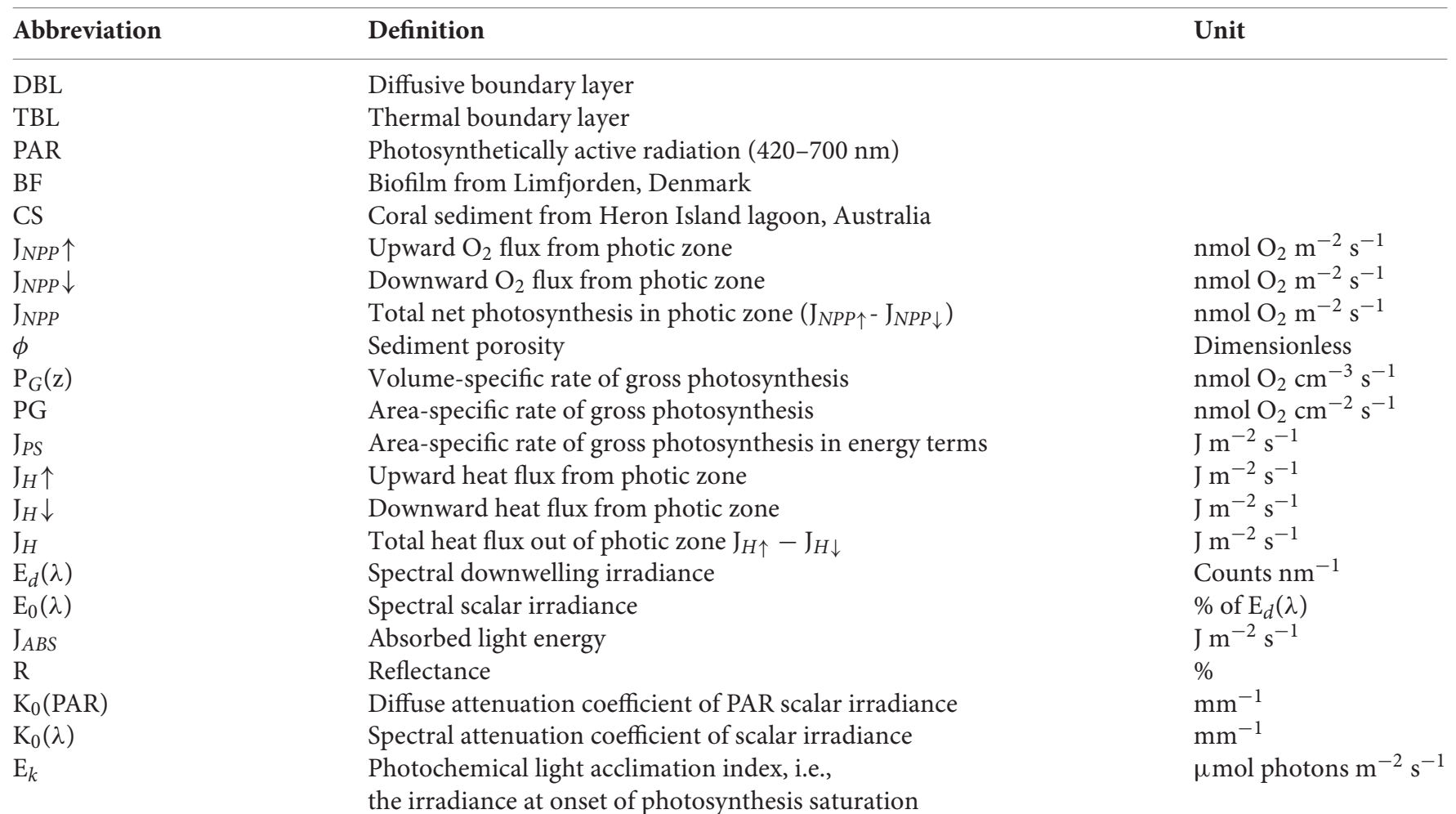

